Portland State University

PDXScholar

\title{
The Development of Community Relations with Low- Socioeconomic Status, Black Communities and Provisional Equity of Fire and Emergency Medical Services
}

Claire R. Rutgers

Portland State University

Follow this and additional works at: https://pdxscholar.library.pdx.edu/honorstheses

Part of the Public Affairs, Public Policy and Public Administration Commons, and the Race and Ethnicity Commons

Let us know how access to this document benefits you.

\section{Recommended Citation}

Rutgers, Claire R., "The Development of Community Relations with Low-Socioeconomic Status, Black Communities and Provisional Equity of Fire and Emergency Medical Services" (2021). University Honors Theses. Paper 1114.

https://doi.org/10.15760/honors.1141

This Thesis is brought to you for free and open access. It has been accepted for inclusion in University Honors Theses by an authorized administrator of PDXScholar. Please contact us if we can make this document more accessible: pdxscholar@pdx.edu. 


\title{
The Development of Community Relations with Low-Socioeconomic Status, Black Communities and Provisional Equity of Fire and Emergency Medical Services
}

\author{
by \\ Claire Rutgers \\ An undergraduate honors thesis submitted in partial fulfillment of the \\ requirements for the degree of \\ Bachelor of Science \\ in \\ University Honors \\ and \\ Economics \& Pre-Medicine
}

Thesis Advisor:

Dr. Tina Burdsall

Portland State University

2021 


\begin{abstract}
The history of the fire service is unique and provides the opportunity for national growth and evolution through local level models of engagement with the Communities fire departments are tasked to serve. There is a specific project in realigning the narratives and improving the relational dynamic between fire service personnel and low-SES Black Communities. The investigation of the relational gap between low-SES Black Community members and fire and emergency medical services (EMS) personnel is conducted through historical investigation and quantitative analysis, situated in distinct moments of amplification that serve as a lens through which the dynamic can be understood. The analytical frameworks rest on the recognition and acknowledgement of systemic structural and infrastructural racism, ghettoization, intergenerational poverty, and social determinants of health that disproportionately affect low-SES Black Communities. The density of identifiable moments depicting clear propagation of the relational gap, social inequality, and interactions between Black Community members and fire service personnel resulted in the 1960s serving as the decade for the moments of amplification and the large-scale analysis of the structural racism built into institutions throughout the United States. The identification of national moments of amplification does not claim to be the origin of tensions between the fire service and Black Communities, however the consideration of two moments in particular; the Birmingham Children's Crusade of 1963 and the Watts Rebellion of 1965 build a lens through which to understand the relational gap. There is a phenomenal lack of literature and interdisciplinary investigation of this field, which breeds the continued propagation of this dynamic, and a lack of awareness that the hegemonic national narrative depicting the fire service and firefighters as heroes, is not universally shared. This work aims to identify and explore the inherent complexities of interdisciplinary contradictory discourse and emphasize the importance of awareness in this field for evaluation and future development of local provisional equity in fire departments across the United States. Humanity necessitates a respect for the work and commitment that firefighters display when they run into burning buildings and scenes of emergency, what has been missing is the trust of the Communities being served and the deeply consequential misalignment of narratives that propagate the relational gap between low-SES Black Communities and fire and EMS personnel. Developed from perspectives gained from relationships with Black Community members and numerous firefighters, supported by literature and academic publications, this work seeks not to charge or prosecute the institutions included in the structural investigation, but rather to outline a dynamic and suggest a starting point for institutions and Community leaders to improve understanding and develop objectives to address dynamics of relational interactions on individual local levels.
\end{abstract}




\section{Table of Contents}

Foreword Acknowledgements $\quad 4$

About the Author $\quad 4$

Statement of Terminology Rationale $\quad 5$

$\begin{array}{ll}\text { Introduction } & 5\end{array}$

$\begin{array}{ll}\text { Background } & 11\end{array}$

Histories $\quad 16$

The United States Fire and Emergency Services $\quad 17$

$\begin{array}{ll}\text { Origin of the U.S. Fire Service } & 18\end{array}$

The Emergence of Emergency Medical Services $\quad 23$

The History of Police $\quad 24$

The Federal, State, and Local Government Role in Fire and Emergency Services 25

African American Participation and Involvement in the Fire Service 31

African American and Black Navigation of American Structural Development 37

Historic Moments of Tension and Dynamic Amplification $\quad 42$

The Civil Rights Movement and the Birmingham Children's Crusade of 1963

The Watts Rebellion of $1965 \quad 45$

1992 Los Angeles Uprising — The Rodney King Rebellion 48

Literature Review and Quantitative Commentary 49

Considerations in Assessing Utilization and Provisional Equity 49

Fire Risk and Socioeconomic Status $\quad 50$

Utilization of EMS \& Social Determinants of Health $\quad 51$

Firefighter Perspectives on Fire Department Weaponization and Importance of Community Trust 54

$\begin{array}{ll}\text { Quantitative Data } & 56\end{array}$

$\begin{array}{ll}\text { Discussion } & 60\end{array}$

$\begin{array}{ll}\text { Conclusion } & 66\end{array}$

$\begin{array}{ll}\text { References } & 71\end{array}$

$\begin{array}{ll}\text { Appendices } & 77\end{array}$

Maps of Los Angeles $\quad 77$

Abbreviations Key $\quad 82$ 


\section{$\underline{\text { Dedication }}$}

To the Individuals who became my Community,

It is the connections with each one of you that framed the development of this work and continuously inspires academic and personal growth. The reinforcement of my character and passion for this field is something that you have all played a part in. Simply put, I would not be who I am and this project would not have become what it is today without all of you being who you are. I am so grateful for you all.

\section{Ray}

There aren't words to encapsulate how much of an impact you have had on me, my perspectives, and the direction of this work. Thank you for enlightening my perspectives through sharing your experiences, elucidating the concealed history of the Black Panther Party. You not only walk the walk, but walk with strong steps. Your work and commitment to social justice has unequivocally gained my respect and the respect of everyone who has been lucky enough to know you.

\section{My Parents}

Mom, the resilience, perseverance, and unrelenting drive that you embody has set an unparalleled example of strength and independence that I can only hope to pass on to my kids some day.

Dad, from your humor to the depth of your passion and so many things inbetween, so much of who I am has been inherited from your character. The sincerity of your belief in possibility continues to galvanize my setting of goals and dogged work to accomplish them.

The two of you laid the foundation for who I have become.

Your support and encouragement provided the opportunities that defined my character and developed the values that have charted the course for my future.

\section{My Friends Turned Family}

What began as strangers sharing a space has become a family that built a home. A home that serves as a center for our Community. Zoe, Sam, Ian, Maritsa, Zoey, Erin, Anna, and Maddie; your support has been invaluable. Thank you for your extensive patience, engagement in conversation, and willingness to be my soundingboards throughout this project. Being surrounded by all of your unique and individual personalities is undoubtedly entertaining and never fails to keep me on my toes. More importantly though, the core values that you all exemplify, inspires everyone around you to be better human beings, myself very gratefully included. Thank you for being you.

Zoe \& Sam, you two are the matriarchal core of what developed into our extensive Community, from initially unconnected individuals to deeply interwoven experiences bonded through our shared space. Neither of you cease to impress, motivate, or amaze me. I am incredibly excited to see what the future holds for both of you and the impact you will have on the future. I feel so grateful to consider you family.

The directory of people who have enriched this work is too great to be done justice through this dedication alone. To those not explicitly mentioned and to those lost along the way, know that your contributions are not forgotten, nor taken for granted. My deepest thanks and gratitude for your presence and perspectives throughout this process.

\section{With Immense Gratitude and Thanks to:}

My Advisor for this Project, Dr. Tina Burdsall for her extraordinary and unprecedented support throughout this project. 


\title{
Foreword Acknowledgements
}

\begin{abstract}
About the Author
My interest and involvement in the fire service began when I was fifteen through a volunteer program with the Marin County Fire Department (MCFD), quickly evolving to an additional internship with Mill Valley Fire Department (MVFD) and following a relocation to Portland, Oregon involvement with Portland Fire \& Rescue (PF\&R). From the first day of walking into the apparatus bay, my passion for the fire service grew and I became dedicated to emergency services. I began working towards my Emergency Medical Technician (EMT) license during my final year in high school, passing the written exam shortly after my 18th birthday. My preliminary involvement in the fire service and emergency medical services (EMS) inspired me to understand more about the structure of fire service organization, station placement, responsibilities, and Community relations and dynamics. One of the first things I noticed and continued to observe was the difference in atmosphere between busier stations and slower stations, the unique Community interactions and perceptions, and the varying mentality that firefighters adopt depending on the types of calls that crews are dispatched to.

I immediately developed an adoration and passion for the fire service and for serving all members of Community. Founded on the significance and importance of teamwork and a reliance on the people with whom you share a fire engine, the fire service embodies the ideals of loyal and dedicated commitment to others. Outlined in the fundamental job description, firefighters are often the first to arrive on the scene of the worst day of a stranger's life and tasked with the duty to stop the bleeding, to minimize the damage, to decrease or make the pain go away, overarchingly, to help any and all members of the Community in times of crisis. The romanticized ideology of firefighters retrieving cats from trees is rooted in actual occurrences, but the true meaning of the work is demonstrated in moments left out of training manuals. Moments in which firefighters take pause in a residential structure fire to lay out protective coverings over familial belongings before dousing the room in foam or water. Or grabbing the family photo album off of the coffee table during egress of a structure fire's primary search for trapped residents or pets to preserve the physical archive of memories in a circumstance of seemingly total loss.

During a conversation with an individual who provided significant insight into perspectives that lack literature and informed my understanding of ideologies shared and taught in low-SES Black Communities, something he said froze my original thought process and immediately elucidated the privilege of my perspective. While aware of the distinct historic events and experiences of fire service interactions with Black Communities, the insufficiency of my consciously-connected understanding of his experiential and historically-based perspectives - the perspective that he reiterated was shared throughout his Community and that was taught to young Black children by older family members and others within the Community - was disconcerting and unnerving. As we talked about his perspective of the fire department and interactions he has had with the fire service throughout his life, he reaffirmed the dynamic I had observed in certain Communities that depicts a single view of emergency services that encompasses the fire service, EMS, and police. Interested to understand more about his perspective, I asked him if he could comment more specifically on the fire department, separated from the police. Bluntly and without hesitation he responded by saying that to this day, he believes firefighters would turn fire hoses on him without pause if given the order. I was appalled at both the concept and the realization of my personal neglect in awareness of the historical significance. The moment deepened my passion for this project as the creation of a source that can be used to increase national awareness and conscious recognition of the deeply rooted misalignment of narratives and contradiction in discourse that further propagates the relational gap between fire service personnel and members of Communities they are tasked to serve.
\end{abstract}




\section{Statement of Terminology Rationale}

While the terms 'African American' and 'Black' define separate identities and experiences, I will be using both throughout this work. This is not with the intention to be disrespectful to any Community or identity, but rather to speak to a broader audience that is composed of scholars with academic interest, agencies using the material as an initial source to evaluate structural organization, and Community members without academic or institutional intentions. Alternating the terminology between 'African American' and 'Black' seeks to conform to academic and institutional standards, while also respecting the currently accepted phrasing within the Communities of which I am focusing my work.

\section{Introduction}

From its origin, the fire service in the United States was structured to be a communal, public service - perhaps the only true public service. The growth and industrialization of the fire service evolved with that of the United States at large (Kelly et al., 2003; NCFPC, 1973). Beginning in the Colonial-era, firefighters were associated with a reputation of bravery, heroism, and saviorship. The reputational ideas were propagated and popularized by the media, and generally reinforced through experientially inherited perspectives in white households of middle- and high-socioeconomic status (SES). The generationally transmitted perspective and reputational correlation were and are not shared by low-socioeconomic status (SES) and Black Communities ${ }^{1}$. Contrasting Community-correlated reputational perspectives was something I observed directly through my involvement in the fire service, as well as an understanding reiterated to me by firefighters I had the opportunity to work alongside, and individuals with whom I built relationships that have first hand experiential insight into historical and present day Community dynamics of urban, predominantly Black, low-SES Communities.

Informal conversations with mentors and Community members from all walks of life further propelled my drive to investigate this drastically overlooked dynamic between observations, historical narratives, quantitative data, and the archive of memories, perspectives, and experiences that have been shared with me, to identify primary constituents in the relational gap. The distinction between qualitative and quantitative equity serves as the source of the discoursal contradiction. Quantitative data illustratively

${ }^{1}$ Community throughout the course of this work will be capitalized to acknowledge and emphasize the significance of the organizational structure. 
suggests provisional equity, however a review of historical contexts reveals that qualitatively, the relationship and dynamic between Black Communities and fire department personnel is fraught with tension, national symbolism, and contemporaneous distrust. The review of interdisciplinary, simultaneous, and intertwined histories, contrasted with quantitative and qualitative equity analyses of emergency service provision, elucidate patterns and the simplified dichotomy of systematically excluded Black Communities and their establishment of autonomous agencies for service provision. Developing an understanding of this patterned dynamic is of particular significance as the systemic exclusion and resulting auto-annexation of Black Communities parallels illustrative interdisciplinary quantitative data that highlights increased utilization of emergency services in low-SES, Black Communities. The fields of literature that will be most distinctly considered include Black studies, history, economics, sociology, urban studies, public health, and urban, transportation, and economic geography.

Overtime, and with the incorporation of many perspectives, I constructed a framework centered on a topic that lacks understanding and emphasis, but that is of paramount importance for successful and meaningful growth of the fire service and the Community relations with low-SES Black boroughs of urban fire department fire management areas (FMAs). It was through this gained insight that interdisciplinary research began to isolate and identify the factors that propagate the observed dynamic between fire and emergency medical services (EMS) personnel and members of low-SES Communities ${ }^{2}$. Conclusions and understanding of this dynamic requires a deeply amalgamated interdisciplinary approach, situating the topic in interdisciplinary fields of academia and examining the seemingly tangential, yet interwoven components that provide context and visibility to the cast of roles that

\footnotetext{
${ }^{2}$ A great deal of analysis was informed through experiential observations and the incorporation of perspectives from individuals within low-SES Black Communities. The fire service and specifically community relations within the fire service is an under-developed discourse, resulting in an overarching lack in applicable literature, research, and commentary into the structure, dynamics, and causality of this relational gap. The hegemonic narrative connects, but differentiates between police and fire services. The perspective within Black Communities does not necessarily reflect this.
} 
contribute to the relational gap between emergency services ${ }^{3}$ and members of low-SES Communities of color ${ }^{4}$.

The structures through which the analytic framework is presented relies on the deconstruction and historical examination of individual and intertwined components that contribute to the relational dynamic. Following the historic analysis, a review of the contradictory literature is conducted and results in the identification of under developed and under acknowledged factors that propagate the gap in Community relations. This work seeks not to charge, prosecute, or assign blame for the creation and propagation of the relational gap, but rather to use history and quantitative data to outline an essential contradiction in the literature that lacks awareness and recognition, and to suggest a starting point for institutions and Community leaders to improve understanding and develop objectives to improve interactions on individual local levels. This work conducts a non-traditional literature review. By the paralleled assessment of historical narratives and quantitative data, the discoursal contradiction can be observed. However, the historical contexts must be situated in and considered through analytical frameworks to better understand and make tangible the evolution of the dynamics and quantitative patterns seen today. The analytical frameworks rest on the recognition and acknowledgement of systemic structural and infrastructural racism, ghettoization, intergenerational poverty, and social determinants of health. Particularly in the evaluation of quantitative data patterns and statistics, there must be consideration of the social and systemic contributing factors, including medical field discrimination, neglect, and abuse that Black people have suffered throughout American history (Washington, 2006; Evans and Gusmano, 2021). While specific examples of medical field discrimination are not reviewed in depth, provided footnotes direct attention to sources unpacking and investigating some of the blatant examples of racially-based medical discrimination and atrocities seen in U.S. history, for example, the Freedmen's Bureau, Tuskegee

\footnotetext{
${ }^{3}$ This work examines the relational gap of the fire service and emergency medical services (EMS), which may be collectively referred to as 'emergency services,' but does not aim to encompass all emergency services in the commentary.

${ }^{4}$ This work specifically looks at Communities with predominantly Black and African American population demographics.
} 
Syphilis Experiment, and the exploitation of Henrietta Lacks ${ }^{5}$. The structure through which Black Communities and Communities of color at large have been isolated and economically suffocated consists of overt and covert governmental legislation and practices, and a generalized lack of deliberate consciousness about the reality of Black experience in the U.S. throughout society at large. Methods of exclusion and isolation - manifested in the ghettoization and infliction of intergenerational poverty—from governmental systems and through legislation are rooted in the foundation of the U.S. government and the delivery of hegemonic narratives against Black people throughout American society.

The 1950s and 1960s serve as incredibly significant decades for the visualization and understanding of low-SES Black Community relations with fire service personnel, additionally national activism of the Civil Rights Movement, growth and representation of the fire service on a national level, vivid social patterns establishing racially homogeneous suburban collectives, the passage of the Interstate Highway Act of 1956, and the decades that largely encapsulated the national transition of blatantly overt systemic racism to legislative and societal covert structural racism. The density of identifiable moments depicting clear propagation of the relational gap, social inequality, and interactions between Black Community members and fire service personnel contribute to the 1960 s hosting the moments of amplification $^{6}$ and the larger scale analysis of structural racism built into institutions throughout the United States. The identification of national moments of amplification does not claim to be the origin of tensions between the fire service and Black Communities. Simply put, the recognition of these moments aims to draw attention to pre-existing relationships and dynamics that found their origin in the systemic racism built into the foundation of the United States. Two moments of particular emphasis will be considered; the Birmingham Children's Crusade of 1963 and the Watts Rebellion of 1965. Institutions,

\footnotetext{
${ }^{5}$ Sources for the Freedmen's Bureau and Tuskegee Syphilis Experiment are footnoted in the Histories Section. For Henrietta Lacks and the exploitation of HeLa cells, see Skloot, 2017. Note, however, that while this novel is decorated and serves as a commonly implemented source of literature in education, the work is not without problematic content and portrayal of the Lacks family. Additionally, see Washington, 2006 for a detailed chronology of the medical discrimination and neglect experienced by Black people throughout United States history.

${ }^{6}$ Moments of Amplification is a term coined to identify the specific moments throughout history where the relationship between Black Community members and firefighters are clearly displayed and can aid in the tangibilization of the patterns observed and relational gap between low-SES Black Communities and fire and EMS personnel.
} 
specifically government institutions, in Black Communities were seen as unabashedly serving mechanisms of overt racial division and further isolated populations based on factors of socioeconomic status and the color of one's skin. Much of the division throughout the United States is derived from generalizations and distinguishing factors of identity that work to categorize populations by ethnicity, race, religion, gender, sexuality, just to name a few. The events of 1963 reflected on the fire service at large, in addition to the hegemonically driven narrative that further separated people based on characteristics of race and wealth-factors significant in the determination of the amount of power that individuals and groups had in United States systems. The individual dynamics that evolved in cities, towns, and Communities across the United States are necessarily individual and unique, driven by local interactions. Some generalizing statements can be made in regards to the patterns displayed and data reported throughout the country, but as development of Community relations occur on a local level, a local example is fruitful for providing illustrative context to this investigation. The city of Los Angeles, California serves as the locality chosen for commentary on the development of the relations between low-SES Black Communities and fire service personnel. Los Angeles provides a specific history of Black participation in the fire department, illustrates urban growth patterns, serves as the location of two prominent moments of amplification, and acts as the city examined to demonstrate the significance and provide a visualization of the relationship between call volume and population demographics. Additionally, the individual who most significantly impacted the direction of this work shared personal perspectives and insights from his experience growing up and living in a low-SES Black Community in Los Angeles. The brief pseudo case study focused in Los Angeles does not seek to insinuate or anchor Los Angeles or the Los Angeles Fire Department to an exorbitant role in the propagation of the relational gap between low-SES Black Communities and fire service personnel, but rather aims to elucidate patterns seen throughout the nation and create a tangible illustration of how seemingly tangential or unrelated factors contribute to systemic gap propagation and inequity. Structural components that are particularly emphasized and visible in Los Angeles include the irregularity in the shaping of LAFD boundaries - correlated with Los Angeles city limits and determined by City officials - that demonstrate 
the fire management area (FMA) boundaries tracing the perimeter of several demographically poor and predominantly Black neighborhoods and Communities of $\operatorname{color}^{7}$ (see Appendix A). Significance of city limits extends far beyond commentary on the dynamic between fire and EMS personnel and Black Community members, through the correlation of city limits with the bounds of public education, utility distribution, and representation in the vote for elected officials and legislative action in nationally significant municipalities. Exclusion from Los Angeles city limits implies fire service provision by either the County of Los Angeles or through the establishment of independent fire departments within the small cities on the outskirts of the urban enclave. While surrounded by Los Angeles city limits, annexed independent cities including Compton and Inglewood demonstrate patterns of structured separation and exclusion. The figures included in Appendix A illustrate Census data compared to fire service station and resource allocation. The inclusion of these maps is significant in highlighting several of the covert structures of racism, however, quantitative data and the statistical analysis demonstrate what could be considered as surprising reports of provisional equality in the historical context of systemic racism. Additionally, the public transparency of the LAFD call tracking system and archive serves as a model for easily accessible quantitative data that can be used for further work and regression analyses to comment more extensively on the provisional equity of fire and EMS (LAFD, n.d).

Quantitative data examined in this work is centered around three intertwined focal points: concentration of fire department call volume and density, two primary categories for Geographic Information System (GIS) models of station mapping, and departmental response times. This data is not confined to fire service provision in Los Angeles, rather it depicts and references nationally observed patterns and data. The data on service provision and suggested equity is not insignificant by any means, but must also be considered through the lens of systemic issues and environmental factors that contribute to the disproportionate utilization of fire and EMS in low-SES Black Communities.

\footnotetext{
${ }^{7}$ See (Brown et al., 2012) for commentary on how the ghettoization of Black folks correlates to the emergence of street gangs.
} 
While firefighters and Community members are collectively aware of the dynamic between fire department personnel and members of low-SES Black Communities, overt efforts to close the relational gap have not been scaled enough to gain national recognition, emphasis, and momentum. Rather than this dynamic being driven by neglect or conscious practices of exclusion reinforcement; the "by Community, for Community" service that is founded on the basis of collective communal collaboration and the public at large generally lack the awareness and literature about historical significance and the contributing factors that shaped the evolution and development of relations with low-SES Black Communities. As stated, there is a phenomenal lack of literature and interdisciplinary investigation of this field, which fosters the continued propagation of this dynamic, specifically awareness that the hegemonic national narrative that depicts the fire service and firefighters as heroes, is not universally shared. This work aims to identify and explore the inherent complexities of interdisciplinary contradictory discourse, and emphasize the importance of awareness in this field for evaluation and future development of local provisional equity in fire departments across the United States.

\section{Background}

The multiplicity of components that factor into the unique dynamics of individual Communities cannot be captured in a single investigation without dilution of substantive conclusions. This work does not attempt to claim that all low-SES Communities are identical, nor that all minority and intersectional identities share an experience ${ }^{8}$. For the purpose of this work I will not be addressing the complexity of intersectional identities. That is not to say that the experience of Black women is the same as Black men, or shared between any two Black individuals for that matter. Further, this work does not seek to imply experiential homogeneity across racial, ethnic, religious, or gender identities. The choice to evaluate the relational dynamic of low-SES Communities of color with predominantly Black populations was driven by personal experiences in the field and insights shared by members of a low-SES, predominantly Black Community in Los Angeles. Additionally, Black history in the United States presents a deep evidentiary

\footnotetext{
${ }^{8}$ See Clarke and McCall (2013).
} 
archive and a unique vantage point to analyze systemic racism and vivid moments of national dynamic amplification that can aid in understanding the observed interactions of the present. The framework I have constructed interacts with an identified contradiction in literature discourses and seeks to present insight for consideration in the improvement of Community relations between fire department and EMS personnel and low-SES Black Community members. The model and method of analysis, however, can be utilized for similar evaluations across numerous socioeconomic status, ethnic, racial, and intersectional Communities.

Through the acknowledgment of race — and racism as the resultant manifestation — as a social construct, materialized by foundational incorporation into United States systems and institutional structures, the notion of systematic exclusion and resulting dogmatic unequal treatment of Black folks becomes tangible and a framework through which the examination of Black systemic navigation and urban infrastructural racism can be situated. Historical analysis illustrates the systemic exclusion of Black people and Black navigation through fundamentally racist social and governmental systems in the United States. Throughout U.S. history, Black and African American systemic navigation through exclusionary structures has resulted in reactionary auto-annexation that demonstrates the construction of independent, self-sufficient organizations. This pattern can be observed through the writings of Dr. Rebecca Crumpler following the failings of the Freedmen's Bureau and the establishment of the Joseph Waddell People's Free Ambulance Service and People's Free Medical Clinics by the Black Panther Party (Crumpler, 1883; Nelson, 2011). With the underlying foundational understanding of Black exclusion from governmental systems and services, the concept of public and Community services becomes increasingly complex and is fraught with required definitional evaluation for terms of service, Community ${ }^{9}$, and equity ${ }^{10}$. The intricacies of this dynamic are further exaggerated through compelling literature that duplicatively concludes fire and emergency medical services are disproportionately utilized by Black and low-SES Communities.

\footnotetext{
${ }^{9}$ Community throughout the course of this work will be capitalized to acknowledge and emphasize the significance of the organizational structure.

${ }^{10}$ See (Lambert, 2017) and (Ahlbrandt, 1972) for explanation of 'public goods' and 'quasi-public goods'.
} 
The interdisciplinary approach takes into account the construction of cities in the context of infrastructural racism through the lens of urban studies, Black studies, and economic geography. Components of inequity extending beyond history in this field are also related to urban waterways, accessible water pressure for firefighters when arriving to extinguish a structural blaze, accessibility of low-SES Community residents to personal vehicles, distance from hospitals and urgent care institutions, transportation accessibility, and neighborhood condition (Kuswa, 2002, Jennings, 2013). This work will not explore all of the above topics, but does aim to comment on the increased fire risk of low-SES Communities and the patterns in fire and EMS caller demographics and dispatch to low-SES Black Communities (Jennings, 2013; Rucker, 1997; Kuswa, 2002; Alter, 2011; Williams and Jackson, 2005).

It is important to consider not only the increased fire risk of low socioeconomic status Communities, but the systemic conditions that contribute to the patterns observed. Infrastructure in low-socioeconomic status Communities does not receive the same level of investment, maintenance, or renovation as do wealthy communities and as a result suffer from degradation and deterioration. This disproportionate deterioration leads to a larger fire risk and is compounded by factors of building materials and overcrowding in residential occupancies (Jennings, 1999). Further, without the accessibility to and generalized inclusion of Black and poor people in receiving healthcare and medical treatment, many poor folks and people of color rely on the care of emergency first responders as a stand-in role of a general physician or nurse practitioner, which increases the concentration of 9-1-1 calls for fire departments and EMS in low-SES Black Communities (Rucker, 1997). There is no obfuscation regarding the health disparities or repercussions that have resulted from the oppression that Black and poor people have faced and continue to experience, which leaves folks with a higher risk of sudden health complications and a larger propensity for several chronic and serious conditions and diseases. (Smith, 2005; Williams and Jackson, 2005).

Urban development plays an incredibly significant role in the evolution and establishment of ghettos — isolated areas occupied by minority groups with similar connotations as slums - much of which is illustrated through economic geography (Logan et al., 2015). The ghettoization of Black Communities 
is examined through interdisciplinary lenses, including the approach taken by authors Blackwell and Bailey, connecting the Black Internal Colony model to the establishment of ghettos and the infrastructurally reinforced, economic isolation experienced by Black Communities (Blackwell, 1975; Bailey, 1973). Infrastructural development that further suffocated Black economies and segregated Black Communities from commerce, transportation, and even communal gatherings can be visualized through the construction of the highway system following the passage of the Interstate Highway Act of 1956 (Kuswa, 2002). The concept of infrastructural racism refers to the physically constructed barriers and boundaries that are created by highways and waterways, for example, that effectively wall off Communities from the rest of the world and isolate spaces as external and contained enclaves that are fortified from the outside in (Bailey, 1973; Marable, 2011; Blackwell, 1975). This can also be seen in the pattern of walls built along the freeways to hide the Communities that exist behind them, as highway systems were built with the intention of delivering resources to the growing suburban populations - specifically the racially homogeneous suburbs fabricated by the 'White Flight' (Kuswa, 2002; Marable, 2011; Logan et al., 2015). Much of the theory around the internal colony argues that Black Community members function as a source of labor reserves and pawns for economic exploitation (Marable, 2011; Bailey, 1973). Ghettoization is the resultant phenomena of infrastructural, physical isolation and the economic deprivation, exploitation, and urban decay of the Communities contained in the urban enclaves (Marable, 2011; Blackwell, 1975). While infrastructural design and development may appear to be strictly on the basis of advancing industrialization, transportation efficiency, and the effective delivery of goods, the underlying intentionality included the isolation, restriction, and control of Black Communities and the structured systematic reinforcement of intergenerational poverty (Kuswa, 2002; Blackwell, 1975, Davies and Huff, 1972).

Quantitatively, GIS station mapping serves as an important indicator of provisional equity as the geographic allocation of resources determines the rate at which fire companies can respond to emergencies throughout a city. The two models include a Euclidean model that is based upon geographical equidistance between fire stations, ideally correlating to equal response provision 
throughout a city, the second model utilizing statistics and data regarding call concentration, population density, and utilization of fire and EMS to determine resource allocation and distribution of fire apparatus (Beaumont, 1981; Corcoran, 2007; Kiran et al., 2020). Both models are correlated to the funding structure and the distribution of financial resources in regards to required apparatus, fire and medical equipment, and personnel compensation (Getz, 1979). The weight of each model employed within different fire departments depends on several factors including the amount of funding received for the provision of emergency services is based largely on the collected taxes—and corresponding wealth—of a municipality, the density of the population, and the region or areas across which fire departments are responsible for providing services ${ }^{11}$ (Beaumont, 1981; Getz, 1979). The dissertation work of Claire Gomersall assesses fire service provisional equity through a geospatial analysis. Through her regression, she demonstrates an inversely proportional relationship between population density and travel time, indicating that emergency services arrive more quickly in areas of higher population density than they would in areas of low population density. This suggests a larger weight put on the equity of provision based on the number of people and percentage of the population served through apparatus distribution. This is important to consider in the conceptual framework of ghettoization of Black Communities and the overcrowding that is demographically reported in low-SES Communities, as fire departments have demonstrated increased apparatus and resource allocation in the areas with the largest call concentration and highest population density.

The origin of the fire service, the American Bucket Brigades — or even further back dating to the Roman establishment the Corps of Vigiles - illustrates the foundation dedicated to the prevention and response to devastation (Quarantelli, 2000). Opposed to the pattern of political militia and oppressive institutions that became what is recognized as the police department (Quarantelli, 2000; Potter, 2013).

\footnotetext{
${ }^{11}$ It is worth noting that the organizational capabilities of urban fire departments are not reflected in rural fire departments, as call volume, population density, and available resources are exceptionally different between urban and rural areas.
} 
There is distinct behavioral repetition during calls in low-SES Black Communities ${ }^{12}$, which highlights attempted individual delineation and differentiation from the police department through phrases along the lines of "we're not the police, we are just here to help," duplicatively recited by firefighters or EMS personnel attempting to provide medical aid to Community members. A course of action taken as a result of the awareness that certain populations have extremely adverse relationships with police and that the external presentation of the fire department can be viewed as a united front with law enforcement. This issue and topic is far from rudimentary construction and isolation from complex societal issues. There is a structured element of necessary cooperation between the fire department, EMS and police. The fundamental and foundational differences between the fire department and police contributes to the historic rivalry between the two institutions and the nuances in public perception. Further, it is the respective origins of the fire service and law enforcement, consciously or otherwise, that differentiates the individuals and the mentality of those who become firefighters as opposed to police officers, and that breeds the insistence of identity distinction between the two occupations. The evolution of the fire service and influence of the federal, state, and local level government has influenced and promoted the intertwining reputations of firefighters, EMS personnel, and police officers, impacting generalized public perception, and informing Community interactions. Historical analysis provides depth and context to situate these models, theories, and observations in the larger framework and arguments of this work.

\section{Histories}

Commentary on the structures that evolved in the fire service and in the United States at large would be out of line if not to first examine the histories that led to its creation. This work includes histories broken into three larger groups; the history of the fire service and emergency services in the U.S., the history of Black navigation, and the analysis of moments of amplification. To begin the structure, origin, and development of the fire service is considered. This analysis will include subsections that

\footnotetext{
${ }^{12}$ This pattern is not solely observed in low-SES Black Communities, but with any population or individual displaying aversion to police presence, for example, calls across all population demographics involving illegal substances and fear of arrest upon admission of the intoxicants used.
} 
elucidate the history of emergency medical services and the police department for background context that leads to the analysis of their reputational intertangling. The structure and evolution of the police department will not be a main subject, however detangling the knotted network of public and emergency services highlights the differentiation between the branches and origins of law enforcement, fire and emergency medical services. This seeks to build an understanding of emergency services at large, their foundations, and the events that led to the intertwined dynamic and observable collaborations throughout the U.S. today. With the focus on low-SES, Black and African American Communities, a brief historical commentary of African American experience is conducted through the employment of specific moments and historical events to illustrate navigational methods of Black and African American people through a belligerently unequal and discriminatory system. African American and Black involvement and participation in the fire service is touched on through a lens of structural development and systemic evolution, though emphasis on the development of the dynamic observed today will result from the examination of historic moments of extreme exacerbation and amplification; the Birmingham Children's Crusade of 1963, the Watts Rebellion of 1965, and the Rodney King Rebellion of 1992. Particular emphasis will be focused on the Civil Rights Movement, the Birmingham Children's Crusade, the Watts Rebellion, and the time period of the 1950's to 1970 's as significant structural changes of emergency services were occurring on the level of the Federal government contemporaneously with increased visibility of movements for social change.

\section{A. The United States Fire and Emergency Services}

Vague and unclear space left in the definition of emergency services would be a disservice in the context of historic understanding and present day perspectives. Specifically, preventing ambiguity in the organizational structure, purpose, and intent of the fire service in contrast to that of law enforcement and the police department. American history truly only includes these two branches, aside from military 
intervention, to be part of the emergency services umbrella ${ }^{13}$. The creation of a healthcare system that began to separately encompass emergency medical interventions and care and the realm of emergency medical services (EMS) was not established until much later than the fire department, and was considered an extension of fire service responsibilities and oversight.

\section{a. Origin of the U.S. Fire Service}

Throughout global history, fires have destroyed infrastructure in urban areas and displaced masses of people. Fires proved to be an instrumental and catastrophic source of devastation for the developing colonial population in the United States. The colonial model of a societally standardized and collectively agreed upon communal understanding of emergency procedural responsibilities built the foundation of 'Communal Firefighting,' the volunteer fire brigades, and the paid, career firefighters that followed. As colonial growth and infrastructural development progressed, the need for a structured fire service was made abundantly clear. The National Fallen Firefighters Foundation (NFFF) discussed the significance of the collective initiative behind Bucket Brigades which served as the most prevalent form of communal responsibility for fire intervention in many Communities (Kelly et al., p. 19, 2003). Bucket Brigades were comprised of men, women, and children who would respond to an incident of fire by bringing loads of water to hand pump engines (HPEs) (Kelly et al., 2003). Proper and efficient operation of the hand pump engines required training, skill, and the strength of a team of people. Overtime Community members who were tasked with operation of the hand pump engines began to develop rhythms and routines with the other members of the Community who volunteered to participate in the mechanical extinguishment process. The organically-formed teams eventually developed and self-orchestrated into organized volunteer fire companies. These emerging fire companies, while quintessential to the preservation of the colonists and colony infrastructure, were not officially endorsed volunteer departments. The fire companies were entirely volunteer based and relied heavily on the colonies for aid. The NFFF recounts

\footnotetext{
${ }^{13}$ Modern history has expanded to encompass Emergency Medical Services as an additional branch, but with significant connection to the fire service.
} 
the common practice of civilians guarding hydrants nearest to an incident, confidently expecting their own volunteer company to arrive and initiate pumping operations from the post. The foundational ideals of the fire companies served as standing guidelines and protocols that members of the Community could rely on and follow in cases of emergency (Kelly et al., p. 20, 2003). The Community-based volunteer fire companies encompassed a social aspect as well and became a place that served Community on multiple fronts, including that of communal gatherings. Kelly and the NFFF highlight that regardless of the formal recognition of fire companies as entities of colonial public service, high standing opinions and support from the Community of volunteer firefighters was unattested, yet the necessity for an advancement in trained manpower and organized departments with full-time crew was not lost on the population (Kelly et al., p. 20, 2003). The growing colonies and size of the population led to an increase in the number of volunteers necessary to protect Communities with climbing numbers of alarm bell activation due to the expanded population. The NFFF recounts that these auto-organized fire companies became the first official fire companies to receive accolades of being the "best local service and people who will do whatever is necessary to rescue and protect civilians even at risk of death" (Kelly et al., p. 21, 2003) in addition to carrying the Community's sense of worth. Years later the Fire Department of New York would write that their firefighters are "strong, able, discreet, honest, and sober men..." (Kelly et al., p. 23, 2003). Regardless of the formal recognition of fire companies as entities of colonial public service, high standing opinions and support of the volunteer firefighters from the Community was unwavering.

December, 1737 brought the establishment of the New York Volunteer Department (NYVD) by the colony's general assembly and resulted in an endorsed station built in front of city hall. This marked the official role and responsibility to protect the municipality from a centralized location. Community support of firefighters was staggering, with civilian descriptors recorded as overwhelmingly positive; dedicated, courageous, and unselfish (Kelly et al., p. 20, 2003). The establishment of volunteer companies increased efficiency and capabilities of fire prevention, protection, and response, however many colonial Communities including Boston, Philadelphia, Charleston, New York, and smaller towns still suffered catastrophic loss at the hands of large-scale fires preceding the Revolutionary War. The Civil War brought 
multiple dimensions and developments to the field of emergency services including the origin of Emergency Medical Services (EMS) and the contributions made to the fire service by "The First Fire Zouaves." Under the command of Col. Elmer E. Ellsworth, the regiment of the Union Army comprised of New York firefighters illustrated the impact and importance of established and structured full-time fire departments. On a temporary station assignment in Washington D.C. the First Fire Zouaves fought the Willard Hotel Fire, creating human pyramids in lieu of accessible ladders for use by fire personnel (LOC, 1861; WHHA, 1861). Their decisions and actions served as huge encouragement for cities to establish "career" departments after witnessing the efficiency of the reliable on-duty forces.

The fire service, particularly the ingrained and precedented nature of volunteer companies, was indubitably constructed with pride, often leaned towards conservative ideologies, and had deeply rooted traditions that seem integrated into the foundation of the fire service as a whole. Traditions were integral to the structured scaffolding on which firefighters emerged and grew into the publicly acclaimed role that highlights heroism and bravery on a national level (Kelly et al., p. 27, 2003). The amount of devastation resulting from extremely undermanned, uncontrollable fires forced changes on the stubborn and proud institution of the volunteer companies. Drastic organizational and systemic changes rapidly commanded authority over the standing structure of the fire service creating additional tension and competition between volunteer firefighters and governmentally endorsed firefighters. Formal interactions and development of government involvement in the oversight of the evolving institution of city fire departments sparked conflicts with the still active members of the volunteer fire companies. Endorsed firefighters were seen by volunteers as catalysts of change and as the individuals responsible for the incorporation of horse-drawn, steam powered pumps with the subsequent phasing out of the hand pump engines that had been in use throughout much of colonial unstructured communal firefighting.

Technological change starting with Boston's self-propelled steam engine in 1872, was quickly followed by surrounding major urban populations throughout the country, further sparking industrial innovation focused on the efficiency of fire apparatus. Interestingly, regardless of the numerous innovations and creations dedicated to fire personnel and apparatus effectiveness, technological expansion 
often failed to increase efficiency and instead was correlated with an increase in the dangers associated with firefighting (Kelly et al., p. 31, 2003). Additionally, there was increased territorial conflict between volunteer firefighters and municipality paid firefighters. The incursion of the paid firefighters onto the historically marked territory of the volunteer companies led to increased tension and not uncommonly, consequential repercussions including the targeting of paid firefighters by resentful volunteers who had been replaced with the establishment of the paid positions. The rivalry between full-time paid firefighters and volunteer firefighters routinely resulted in fierce and bitter competition between volunteer hand pump engine operators and full-time steam pump engine operators, which later became full-time horse-drawn operators followed by motorized engine operators. A massive overhaul occurred within fire service organization and leadership, though several original volunteer company traditions remained engrained in the firefighters as irrefragable characteristics that define the fire service as a whole. Firefighters had a reputation for "taking the punishment" without much or any thought regarding firefighter safety or tactical risk assessment and blatantly ignoring potential — typically probable — consequences of their actions (Kelly et al., 2003). The rough and tumble temperament of firefighters paired with the Community views and opinions of firefighters and in-house dynamics encouraged a stubborn commitment to the character-defining "smoke eater" status of many urban firefighters.

From the establishment of the colonies and the devastatingly epiphanic Jamestown Fire in 1608, the fire service began its maturation from the Bucket Brigades comprising all members of what was then, a clearly defined Community. The fire service grew from the expanding needs catalyzed by industrialization, with the principle foundation arising from a one for all, and all for one mentality. To be a member of the fire service, to be a member of a crew tasked with responding to public emergencies was viewed as a position of great respect and social recognition (Kelly et al., p. 19, 2003). Prominent members of American history served as leaders or volunteers in the fire service, including Samuel Adams, John Hancock, Paul Revere, George Washington, Benjamin Franklin, John Jay, Alexander Hamilton, and Benedict Arnold. The 1860s and actions of "The First Fire Zouaves" during the Civil War-under Colonel Elmer E. Ellsworth — propelled the development of the fire service from an obligatory expectation of 
Community members, to a recognized occupation of the service that required dedication and specialization. The ideology of Community members serving the entirety of the Community through emergency response remains a quintessential component of the fire service and a principle that defines the generations of firefighters who follow in the footsteps of the Bucket Brigades.

As the United States continued to develop urban centers, innovative ingenuity catalysed technological evolution. The national experience with large-scale loss continued to set a dangerous and attention-demanding precedent, necessitating the call for the establishment of full-time fire departments, staffed with paid career firefighters. The evolution of the fire service from the Colonial era through the 19th century took three distinct forms that comment on the development of the United States through communal firefighting operations, to the necessary creation of organized volunteer fire companies, to the establishment of structured fire departments with full-time, paid firefighter positions. The U.S. Fire Administration — originally titled the National Fire Prevention and Control Administration (NFPCA) - was officially implemented in 1974 under The Federal Fire Prevention and Control Act which encompassed the establishment of an agency with a Presidentially appointed administrator and direct communication with the Secretary of Commerce (Reeves, 1980). The work of the International Association of Fire Chiefs (IAFC) resulted in the appropriation of federal funding for training and research to various states, the ability to introduce legislation to Congress on behalf of fire necessities, and a representative body of the fire service at the federal table. One of the most significant texts that brought light to the needs of the fire service was America Burning, which provided thorough documentation and resulted in broad public support for federal action (Reeves, 1980). Fire departments provide mutual aid with surrounding companies and as a result of the standardization set by the state and the IAFC, firefighters are able to provide that support on the scene of incidents with volunteer or professional fire crews from surrounding fire departments (Reeves, 1980). In many ways, as the country evolved so did the fire service. 


\section{b. The Emergence of Emergency Medical Services}

Similar to many American and global innovations, much of the fire and emergency medical services' evolution was driven from military and battlefield necessity. The Civil War brought the emergence of field ambulances, some of which were operated by the 'Fire Zouaves' (Forster, 2014). The Industrial Revolution brought about private urban ambulance companies, but for rural Communities the prospect of medical aid had to come from volunteers within the fire department; as basic as their knowledge and skill was. Some of the earliest medical care provided to Communities was in the 1930s with minimal rescue aid services offered to Community members in times of crisis (New York State Military and Veterans Research Center, n.d.). The 1960s gave way to the increase in medical knowledge expectations for firefighters in airway management and fluid replacement (Institute of Medicine, 2007). The true foundation of American Emergency Medical Service (EMS) was in 1966 following the establishment of the National Highway Traffic Safety Administration (NHTSA) (Shah, 2006; Institute of Medicine, 2007). The International Association of Fire Chiefs (IAFC) documents that in the late 1960s and into the 1970s firefighters in several cities across the United States became some of the first paramedics (IAFC, 2009). The IAFC issued resolutions of support for evolution of firefighters being medically trained in 1975. In the U.S. today it is a requirement for almost all firefighters to have earned their Emergency Medical Technician (EMT) license or their paramedic license. This progression is a result of the continual expansion of the fire department's scope of practice and response expectations. Structures of emergency medical care provision vary in cities from overarching supervision of EMS by the EMS Chief within a fire department, to baseline medical training for firefighters with one paramedic per apparatus in addition to a city contract with a private ambulance company to act as patient transportation and medical response only (Institute of Medicine, 2007). Another system is one wherein the fire department staffs an ambulance with medically trained firefighters who can serve in dual positions as EMS personnel and firefighters, and while there is support in the fire service for this system, the structure is often more common in rural departments. 


\section{c. The History of Police}

The origin of the fire department is rooted in Community, a necessary reliance on unity, and the dedication to serving and protecting the Community of which individuals were a part (Kelly et al., 2003). The police department originated with the foundational purpose of tracking, catching, and reimprisoning slaves - freed and otherwise. The initial watchmen that would later form constables and eventually, police departments began as voluntary committees or required rotations within Communities as a deterrent body for crime, however this organization proved unsuccessful as many of the watchmen would drink or sleep while on duty (Potter, 2013). Coupled with resentment from Community members that they were not receiving compensation for the position, the resulting development was the privatization of police and the development of for-profit services, including the tracking and bounty hunting of freed and escaped slaves (Spitzer and Scull, 1977; Hadden, 2001, Hansen, 2019). The generation of the notion that police and law enforcement were to be a communal service and the collective good was the result of merchants attempting to avoid incurring the cost of privatized protection services by employing the argument of the free rider problem (Potter, 2013; Spitzer and Scull, 1977; Hansen, 2019). The slave patrols that became police were legally sanctioned before the Civil War (Turner et al., p. 186, 2006). The institutional evolution from slave patrols to police stations and departments cannot be overlooked in the identification of sources in the propagation of systemic injustices. Additionally, the connections and correlations between police and the Klu Klux Klan acted as one of the driving motivations behind the passage of the Klu Klux Klan Act in 1871 (Kappeler, 2006). Slavery was not limited to the South, nor was racism, or the opposition to Reconstruction, but previous Confederates often exacted more oppressive regimes and horrific treatment of Black people, continuing into the Civil Rights Movement of the 1960s.

Over the course of American history, preceding and following the Civil War, law enforcement and police officers have displayed patterns of brutality, discrimination, and unequal treatment of African American and Black people. The 1960s encompassed changes in the structure of the police department including unionization in response to legal matters of police brutality (Potter, 2013). Through the decades 
of the Civil Rights Movement, police departments were tasked with the responsibility to respond and control the demonstrations for racial equality and riots of charged civil unrest that took place around the country (Potter, 2013). It became standardized to expect paddy wagons at the scenes of demonstrations for mass arrests of Black activists. These mass arrests commonly took place during peaceful protests, marches, and demonstrations. The habitual law enforcement use of billy clubs to beat and subdue people of color was not limited to the demonstrations during the Civil Rights Movement. Countless examples of police brutality and the mistreatment of people in police custody, including the use of deadly force against innocent and unarmed Black Americans, are spattered throughout history, up to and including the present. In considering the function and observed interactions between police and Black Community members, it is paramount to consider the social construction of racism and fundamentally racist principles that institutions across the U.S., including and particularly the police department, were founded on. Further, to recognize the significance of the origin of the police department that led to the development of the organization and patterned actions that have been witnessed throughout U.S. history.

\section{d. The Federal, State, and Local Government Role in Fire and Emergency Services ${ }^{14}$}

As public services, emergency services (fire, emergency medicine, and police) had a categorical affiliation with one another, but the intertwining and relationships between the services did not originate at the time of organizational establishment. The fire service and emergency medical service forged a connection early on as a result of the First Fire Zouaves and the incorporation of emergency medical training and response into the fire service scope of practice. The development of a relationship with police departments, on the other hand, was much more tenuous and convoluted. There are several levels and components that require consideration to build a thorough understanding of this dynamic; federal involvement, state interaction, local government oversight, and the perspective of Community members ${ }^{15}$.

\footnotetext{
${ }^{14}$ The evolution of Emergency Medical Services on the federal and state levels are not referred to directly. While EMS has also evolved on the level of the Federal and State Government, this subsection encompasses EMS as an extension of the fire service.

${ }^{15}$ See "The Federal Role in Local Fire Protection" for more information regarding the Federal Government's role in rural fire provision and the U.S. Department of Agriculture, Forest Service Rural Community Fire Protection Program.
} 
From the origin of the fire service, local government and direct Community involvement has been the primary body of control, resource allocation, and discretionary action (Reeves, 1980). While federal organizations cooperated with local agencies in fire mitigation and prevention, it wasn't until World War II that the federal government began developing a tangible relationship with the fire service through the distribution of surplus equipment. In the early 1960s, the federal government's involvement with the fire service became more prominent with the accentuation of rural civil defense in response to the Cuban Missile Crisis (Reeves, 1980). The International Association of Fire Chiefs (IAFC) formalized their initiative for a "fire spokesman" to represent fire service interests on the federal level, further driven by discontent over the existing representation of law enforcement on the federal level (Reeves, 1980). The interests of police departments received a voice and representation through the Department of Justice's Attorney General and the Director of the Federal Bureau of Investigation (FBI), roles established in 1870 and 1908, respectively. In 1962, IAFC took measures to ensure the maintenance of local control and insisted on inclusion in decision making to prevent the federalization of the fire service, particularly after neglecting to consult fire service leadership in the construction of fire service dependent civil defense plans (Reeves, 1980) ${ }^{16}$. Local provision and oversight are crucial for fire departments as service needs are Community-based and uniquely tailored to Community needs.

The intent of the fire service's endeavor to involve the Federal government in local provision of service was rooted in creating the deserved representation on a national scale, bringing attention to the need for fire prevention and control research, and the acquisition of Federal resources to sustain service provision, when Community revenue alone is unable to support the services. In addition to defining the fire problem and outlining the 12 Statements of National Significance, the 1966 Wingspread Conference highlighted the importance of economic and financial feasibility research to evaluate the needs of the fire service. Introduced in the statement:

\footnotetext{
${ }^{16}$ The utilization of the fire department in measures of civil defense largely refer to the proactive prevention plans for large-scale fires in the plains and wildland. See Reeves, 1980.
} 
The economic base of the community may place such heavy demands on the service dollars available for all local government functions that the financing of the fire function cannot be afforded at the local level. (Wingspread Conference on Fire Service Administration, Education, and Research, 1966)

Followed by a later statement expressing the necessity of performing a cost analysis to determine the feasibility of isolated local government economic service financing.

In the "Consumer Protection Message" to Congress, Lyndon B. Johnson expressed the significance of Federal involvement in fire protection and prevention:

We must begin by developing improved information about the number and causes of fires and their costs in terms of property, lives, and injuries. The federal government must also begin to support and supplement private research efforts on fire fighting and fire prevention. It should work to expand public education about fire prevention. It should extend a helping hand to communities willing to innovate and experiment in the field of fire control and prevention. (Kerner, 1968)

The Omnibus Crime Control and Safe Streets Act of 1968 established the Law Enforcement Assistance Administration (LEAA), an act of Federal endowment directed to police forces. This allocation of federal support did more than add fuel to the well established rivalry between the fire service and law enforcement, in that it created an agency that the fire service did not have interest in duplicating while making firefighters feel that the opportunity to gain federal assistance for fire service interests had been diminished (Reeves, 1980). Federal assistance and resource allocation drove much of the Federal-level tensions between fire and police services.

One of the largest developments that resulted from federal-level representation of the fire service and police departments was the creation of the 9-1-1 dispatch system ${ }^{17}$. The International Association of

\footnotetext{
${ }^{17}$ The system used prior was a telegraph alarm system, and a bell system before that. See (Till and Coon, 2019).
} 
Fire Chiefs begun recommending single, nation-wide number for civilians to report fires in $1957^{18}$. Several fire departments had installed public phones in cities that connected Community members directly with fire departments to report emergencies and fires, and rapidly initiate response from fire crews prior to the recommendation of the IAFC. On the national level, there was little movement until 1967 and the recommendation by the Commission on Law Enforcement and Administration of Justice, under President Johnson, to create a single-use number that was universally dedicated for civilians to report emergencies to the police (Walker, 2011; U.S. Department of Transportation, et al., 1979). The recommendation was supported by multiple federal agencies and despite the opposition from the telephone industry, the project was transferred to the Federal Communications Commission (FCC) (Walker, 2, 2011). The United States was not the first nor the only country to begin establishing a universal system for emergency reporting and response. The inclusion of fire, police, and emergency medical services under one universal number resulted from the support the initiative had by several federal agencies, including the IAFC, the investigation conducted in Britain in 1937 that determined increased efficiency of emergency response from a shared emergency operator dispatch centers, and the international models of universal emergency response numbers (Walker, 2, 2011; Pozner et al., 2004). The first 9-1-1 call and implementation of the new emergency response system occurred in 1968 in Alabama, followed by Alaska, and quickly spread to cities across the U.S. The monumental implementation of the 9-1-1 system provided many benefits and increased efficiency of emergency response, while also strengthening the correlation between the fire and police service on a national level and in the eyes of Community members who would know use one telephone number to trigger response from either police, fire, EMS, or any combination of the three branches.

State-level roles in the fire and police services can vary with the location and institutional organization of the agencies. Generally, states create and distribute public fire education programs, oversee fire data collection and analysis, adopt state-wide personnel standards, and proctor fire instruction

\footnotetext{
${ }^{18}$ Some sources cite the National Association of Fire Chiefs, however, as widely as it is cited, the organization's actual title is the International Association of Fire Chiefs.
} 
and training (Reeves, 1980; see also State Government Fire Programs, 1977; and NFPA et al. 1977). This structure allows communication between the State and local fire departments and general interagency protocol compatibility, while maintaining local control over individual departments. If provisionally necessary, States can also legislate the construction and operation of local-level fire protection, with State oversight as to standards of training, funding, personnel, and other departmental details (Reeves, 1980). This level of state involvement is generally seen in areas unincorporated by city limits or agencies that serve multiple counties. Agencies that fall under state provision include wildland-based firefighting organizations, for example Cal Fire or law enforcement authorities like the State Troopers. Established local fire organizations are able to maintain more autonomy and interact with state oversight primarily for purposes of resource allocation, protocol standardization, and data collection.

Economics and the significance of funding is a cornerstone in the development of reputational entangling and connection between the historically rivalrous fire and police services. On the level of the federal government, the two institutions signified locally developed agencies that provided services to the public and required Federal resources to meet provisional standards. Though, the fire service was not constructed or employed in the same manner as the police department in regards to the law and imposition of governmental structures of power ${ }^{19}$. With that said, both widespread, locally duplicative agencies benefitted from national representation and the basic organizational standards that a body of departmentally connected leadership can provide. States serve as data collection and resource distribution authorities with a more substantial and active role in emergency service provision in agencies and areas

\footnotetext{
${ }^{19}$ Numerous court rulings have made clear that police officers do not have a legal "Duty to Act" including (Warren v. District of Columbia, 1981), (Castle Rock v. Gonzales, 2005), and (Lozito v. New York City, 2013). Worth noting, the notion of "Duty to Act" and the Code of Ethics can be departmentally and legally different for firefighters and EMS personnel than it is for police officers and law enforcement. Clarity to the specific differences in the eyes of the law will be further distinguished as future court case decisions are made, however a specific area of increased accountability is correlated with the medical responsibilities of firefighters and EMS personnel, the legality of medical negligence, and Community expectations of fire and EMS personnel. A Duty to Act can be binding in departmental policy and/or state legislation. State-wide Duty to Act legislation has been recently written in select states and serves as a legal reinforcement of principles outlined in institutional mission statements and with Community expectations. While I cannot speak for police culture, fire department culture strongly objects to an individual's failure to respond or act on the scene of an emergency with a present fire crew, unless actions contradict standard operating procedures (SOPs) or there is a conflict of interest; an emergency involving a firefighter's family members as the injured patients, for example. This is the result of the unity within fire crews and a shared dedication with the understanding and accepted risk associated with job responsibilities.
} 
outside of city limits or county lines, for example Cal Fire or the State Troopers which are directly overseen by the State (Reeves, 1980). Locally, annual taxes provide Community-based funding for local fire and police agencies. This perceived lumping of funds contributes to the intertwined reputation of fire and police services within Communities, further supported by architectural symbolism in the physical connectedness of police and fire departments.

While finances and funding play significant roles in public and Community perception of emergency services, another factor that served as a correlative link was the utilization of the term “communal service." From the establishment of the government funded police department, the term used in the argument by merchants to transfer the financial responsibility of crime prevention onto the government was that the service provided would be a "collective good" and a communal service through the argument of the free-rider problem ${ }^{20}$ (Potter, 2013; Spitzer and Scull, 1977). The designation as a collective good and therefore a service that should be funded by the Community as a whole, categorized the police and fire services under a similar organizational umbrella of communal services.

Generally speaking, the legislative and governmental complexities in development of the fire service and law enforcement were not followed by the public. Community perceptions of the connections between the two services, however, were in-part built from the observable changes on the local level resulting from the shared funding structure. The parallel fundamental characteristics on the institutional level fire and police departments include city funded stations established throughout Communities. Over time and particularly in the 1900 s, local government funding of police and fire departments occasionally resulted in infrastructure and architecture split down the center, with both services sharing a physical location. The fire department has a unique need for specifically designated distances between stations and the locations of apparatus. Unlike police, which have one or a few main station hubs and deploy police vehicles throughout the city as mobile units of city patrol, fire departments operate under geographically organized fire management areas (FMAs) that are served and taken responsibility for by designated

\footnotetext{
${ }^{20}$ The free-rider problem is an economic phrase to capture the phenomena of a cost for a good or service incurred by an individual or a particular group of people, that has positive externalities or benefits to the general public, whether they contributed to the procurement of the good or service or not.
} 
stations throughout the city. As illustrated by the First Fire Zouaves, the efficiency and level of service is drastically improved through the establishment of professional crews dedicated to emergency response (Kelly et al., 2003). These FMAs are not flexible or changed depending on the staffing of the station or day of the week, but rather are fixed and designed around established station locations and Community needs with a purpose of providing equitable response and protection to all areas within the boundaries of the fire department as a whole (Kelly et al., 2003; McAllister, 1976; Toregas et al., 1971). The inferred reputational correlation that connects the fire and police departments in the eyes of Community members is established on the basis of federal, state, and local tax distribution and funding structures, historic phrasing of communal services, designation as public services, observable similarities in the architecture of fire and police departments, and the shared 9-1-1 emergency dispatch system. Not to mention the interaction and cooperation between the two services outlined in official protocols on the federal, state, and local levels. Community perceptions of the relationship between the police and fire department are influenced by federal and state level developments to a degree, but the crucial beliefs that Community members adopt about the institutions responsible for serving their Community are dependent on local representation, Community involvement, and actions taken by members of local fire, emergency medical services personnel, and police.

\section{e. African American Participation and Involvement in the Fire Service}

The establishment of the fire service serves as a reflection of American history, but beyond serving as mirrors of the social dynamics stations and crews were placed in, there was an overarching pride, duty, and respect for service that separated the fire service and members of the fire department from the general population. It was because of this service and duty that the fire service earned much of its acclamation, but the fire service would not have taken its shape if not for the involvement of Black people, beginning in the 1800 s. The fire service did not act as a catalyst for Black rights, but starting in the 1700s, saw inclusion of Black people and while structural and systemic racism persisted, the titles and treatment of Black people, did in some ways, illustrate the societal contributions and dedication of Black 
people to Communities across the country (Legeros, n.d.). With various sources of motivation, the enlistment of Black folks in the Union Army contributed to the progress of acceptance and equality from white counterparts. The 1780s saw the first Black female firefighter, who despite her status as a slave of one of the New York City Firefighters, earned respect, recognition, and from some, adoration in the Community through her service (Kelly et al., 2003; Legeros, n.d.). In 1871, after serving in the Cambridge Fire Department for roughly twenty years, Patrick H Raymond was appointed to the position of Chief Engineer (meaning Chief of the Department), he is said to be the first Black Fire Chief in the United States (Legeros et al., n.d.). Regardless of color, there were consequences-social and monetary - that resulted from desertion or neglect to respond to the bells that signaled an emergency ${ }^{21}$. Fire crews were incredibly competitive and hostile towards each other, as the order of crews arriving to the scene of the emergency dictated the level of Community respect they would receive. Black individuals, particularly in the South, were recognized for their physical capabilities and in some cases their ability to steer horse pulled cargo. These two characteristics encouraged organized fire crews to incorporate Black people into their crews to increase their speed, efficiency, and response times to emergencies (Legeros et al., n.d.). Black freedmen and slaves were compensated and monetarily incentivised for their service in the fire department, though compensation was significantly less than what white firefighters received.

It is rather common knowledge that the fire service, from the origin of recognizable organization, was constructed by the "strongest, fastest, and bravest men in the Community." That is not to say that women did not play a role in the fire service or extinguishment of fires that broke out, but men were traditionally the driving forces that quite literally ran the pumps to the location of an incident and began physically pumping water onto the flames. This macho dogmatic stigma carried through the times and challenged men to be tougher, braver, and stronger than other men and crews alike; in many ways this was a physical show of power and authority over each other (Dana, 1858; Kelly et al., 2003). The propagation

\footnotetext{
${ }^{21}$ Historical context further distinguishes the Duty to Act between fire service personnel and law enforcement officers, see Footnote 19.
} 
of this mentality led to physical fights that would break out between fire crews, sometimes at emergency scenes. Men that worked in the fire service often tied their pride and what they considered manhood to be their identity in the fire service. This dynamic crossed with the societally propagated visceral exertion of power and authority over Black people — especially in the South—were the reasons that the improved efficiency and response times with the incorporation of African Americans in fire crews, was met with actions taken by some all-white crews against their inclusion (Legeros et al., n.d.). It is also why efforts made by Black firefighters to establish their own crews were opposed by solely and predominantly white crews. Black fire crews had significantly more complex barriers to entry, and slanderous publicity spread through the Community serving as tactics of prevention, for example, to overcome. Many white firefighters did not want Black people to earn and receive the same level or anything close to the recognition and respect that white firefighters received from the Community. More often than not, the all-white fire crews were able to rally public support and enact oppressive policies to prevent inclusion of Black folks in Southern fire departments (Dana, 1858). Notably, this was also the time that the clout of the Klu Klux Klan was increasing, the Freedmen's Bureau had collapsed, and the freed slaves were given absolutely nothing to establish successful lives as free people.

The fire service at large is a field with sparse literature, and thus, Michael J. Legeros' publication with significant contribution by Chuck Milligan and Rev. Ron Ballew constitutes the most expansive source for the national history of Black firefighting. While this source is not published in an academic journal, the research and writings of the recognized contributors is cited in other documentation and review of African American involvement in the fire service.

Statements in reference to the general evolution of the fire service can be made, however the development for individual departments across the country were not identical. As aforementioned, the interactions of fire departments with the Communities they serve determine the relational dynamic on the local level. National imagery and representation impact the level of trust Community members have in the firefighters serving their Communities, but generalized statements of fire service actions are unable to significantly contribute to the explication of observed interactions between specific fire departments and 
the individual Communities they serve. As the Watts Rebellion will be discussed, the history of the Los Angeles Fire Department (LAFD) is of particular substance. Institutional segregation and the fight for desegregation within the LAFD was a drawn out and agonizing saga, largely under the leadership of Chief Engineer Alderson, appointed in 1940 (Ditzel, 1986). Black firefighters, under the 14th Amendment and the support of the NAACP, had varying perspectives on the issues of segregation and desegregation of the fire department. Dating back to before segregation legislation, the first Black participant in the Los Angeles Fire Department was a man by the name Sam Haskins in 1892 (Ditzel, 1986; Burton, 2021). Sam Haskins was not a full-time firefighter, but worked in the paid position as a Call Fireman (a part-time paid position to fill in for sick or absent firefighters). Fireman Sam Haskins was the first member of the LAFD to die in the line of duty, but his service and well-liked personality drove Councilman Ashman to direct the Fire Commission to establish an Engine Company composed of Black men (Ditzel, p. 146, 1986). Sam Haskins's funeral was attended by prominent members of the LAFD and a detail of 30 LAFD personnel, as well as a personal address given by Chief Moore. Following Call Fireman Haskins, George W. Bright was the first Black fireman hired as a full time member of the LAFD in 1897. Bright's promotional progress pushed him to become a certified lieutenant, though attaining endorsement from his Minister and congregation was a requirement as a result of his being the first person of color to express such intentions of advancement.

Segregation in the LAFD was initiated as a result of Bright's promotion and an opposition to a Black man commanding white firefighters (Ditzel, 1986). This stance on Black leadership in the LAFD led to the creation of Black only fire companies and stations. The changing demographics in the city at the beginning of the 1900s led the City Council to direct the reassignment of Black firefighters from an all-white FMA to Station 30, located in a neighborhood of mixed racial demographics. To be staffed by a crew of all-Black firefighters, Engine 30 required an Engineer to be on the crew. At the time, the LAFD had a policy restricting the Engineer certification for African Americans. The discriminatory policy, in addition to the rejection of acting Chief Engineer O'Donnell—-the only member of the LAFD with authority to designate station assignments — of the City Council's attempted interference in the internal 
affairs of the fire department, Chief O'Donnell refused to remove the white firefighters from Station 30 (Ditzel, 1986). The process of relocating the white firefighters from Station 30 spanned seven years and was fraught with mounting racial tensions within the department. Increasing numbers of Black firefighters in the LAFD resulted in the creation of the second all-Black crew, housed in Station 14 in 1936. White firefighters vandalized the station in response to being transferred from the station and were reprimanded by their Battalion Chief ${ }^{22}$. Staffing policies to ensure the necessary amount of Black personnel at Stations 30 and 14 were taken against civil services regulations, wherein up to 400 white candidates would be eschewed to reach the name of a Black candidate.

There were multiple perspectives of the segregated system from Black firefighters and Community leaders, but it was the young, LAFD career-oriented, Black firefighters who felt restricted by limited mobility within the Black fire companies and sought complete integration of the fire department (Ditzel, 1986). Chief Engineer John H. Alderson, while personally supportive of segregation, rejected the popular idea of establishing a battalion ${ }^{23}$ of Black firefighters, and rather opted to initiate a slow process of integration in the LAFD. The group of young, Black firefighters aimed to achieve rapid and forced integration, an approach that Chief Alderson responded to with claims of deleterious impacts on efficiency and morale throughout the department (Ditzel, 1986). Census data from 1954 illustrate the disproportionate representation of Black LAFD firefighters in comparison to the Black population of the city served by the LAFD, 3\% and 10\%, respectively (Legeros et al., n.d.). The NAACP supported the "Petition Concerning Racial Discrimination and Segregation in the Fire Department" which alleged that Black firefighters were being denied equal protection of the laws (Ditzel, 1986). Majority white opposition to integration of the fire department resulted in the ostracization and even disciplinary actions of white firefighters in support of desegregation. The reassignment of Black and white firefighters unopposed to integration sparked the "Hate Houses," located in mixed race neighborhoods, in which all

\footnotetext{
${ }^{22}$ A Battalion Chief is a leadership ranking below a Division Chief, Deputy Fire Chief, and Fire Chief, in charge of overseeing stations within specific battalions of the larger fire department.

${ }^{23} \mathrm{~A}$ battalion is the collection of several fire stations in a geographic region of department territory that is overseen by a Battalion Chief. It is commonplace for urban fire departments to be divided into battalions.
} 
firefighters were subjected to degradation and humiliation by station outsiders (Legeros et al., n.d.; Burton, 2021). Black firefighters assigned to white stations opposed to integration were often denied kitchen privileges and severely hazed. Fire Station 10 was a particularly notable center for the mistreatment of Black firefighters.

Black firefighters organized the Stentorians - a group committed to the protection and patrol of Black firefighters at Station 10 - and were supported by a news station and supplied with microphones to capture the severity of the hazings (Ditzel, 1986). Media interest in racism of the LAFD grew and the department's response was the Station 78 subterfuge, in which Black and pro-integration white firefighters lacking any amount of familiarity with the exceedingly complex and confusing Station 78 FMA were assigned as the station crew. Media coverage captured the crew struggling and falling short of the efficiency standards held by the department, resultant in the separatist agenda-aligned perception that forced, rapid integration led to increased hazard to residents of the area and poor, inefficient fire protection. The intensity of integration support and opposition heightened, with slow progress and setbacks in the desegregation of the LAFD that resulted in the retirement of Chief Alderson in 1955. The long and contemptuous struggle for integration of Black firefighters made quick progress under the newly named Chief Engineer, William L. Miller (Ditzel, 1986). In 1956, all Black firefighters had been transferred throughout the city, to 17 of LAFD's 91 fire stations. It is worth noting that Chief Alderson had no support from the deceptive Mayor Poulson, extremely limited support or directional instruction from the Fire Commissioners appointed by the mayor, and no aid from the City Council (Ditzel, 1986). In the years following integration the achievements of Black Los Angeles firefighters would have national level impacts on African American involvement in the fire service. A particularly significant accomplishment was that of James Shern who became the first Black LAFD Battalion Chief, followed by the Fire Chief of the Pasadena Fire Department, and in 1975, Chief Shern was elected President of the IAFC (African American FireFighter Museum, 2021). The evolution of segregation and integration in the fire department took over half of a century to reach a semi-stable equilibrium, however, disputes on the basis of race and sex were not absent from LAFD history that followed integration. 
African American and Black firefighters had an integral role in the structure and development of the fire service beginning in the 1700s. While the fire service did not serve as a catalyst for Black equality, the history of African American involvement in the fire service has a multiplicity of implications and potential for improvement in the fire service, including the navigation of civil unrest, implementation of fire crews representative of population demographics, and developments of service initiatives with the potential capacity to impact relations between low-SES Black Community members and fire service personnel.

\section{B. African American and Black Navigation of American Structural Development}

The history of African American and Black people in the United States is far from honorable, just, fair, or inclusive. Slavery etched a horrific beginning of African American and Black folks' presence in the United States into the stone of American history. Treatment of people of color was vial and irrefutably cruel. Under white ignorance and social hypnosis, oppressive and false ideas about the experiences and inferiority of African American people spread throughout populations of white people, allowing and in many cases encouraging the indignation. Resulting from the work of Josiah Nott, Louis Agassiz, and Dr. Samuel Morton, the false, yet popularized ideas included that African American people were genetically different than white people and therefore African Americans and Black folks were less capable, less intelligent than white people, and not only less human, but a different species altogether (National Museum of African American History \& Culture, 2020). The 1857 decision in the Supreme Court case Dred Scott v. Sanford speaks to the penetration of racist beliefs and fundamental phrasing that resulted in Constitutional inequality (Taney \& Supreme Court of the United States, 1857). The slow education of the popularized falsities in the North began with the shift in understanding and empathy for the experience of Black people, synchronously with the mounting fundamental economic disagreement between the North and the South regarding the direction of industrial evolution. North of the Mason-Dixon line industrialization and innovation had begun stimulating the economy. South of the 
boundary there was little industrialization, leaving the nearly absolute agricultural economy reliant on physical labor, predominantly the physical labor of slaves (Hughes and Cain, 2011). Free Northern states and the creation of the underground railroad siphoned enslaved people to the North where they could be free, but not equal. Some argue the rejection of this ideology by white people in the South, who exacted total authority and control over Black people, was in response to their personal and ancestral experience of being powerless and without authority in the relationship with the British - that the authority and immense power exerted over Black people, similarly to the horrific actions taken against the Native Americans, further propagated the pattern of their own experience. Economic theory of factor endowments and environmental conditions suggest an additional outline for the institutional and economic development of systemic inequalities (Sokoloff and Engerman, 2000). The severity of structured inequality of wealth, human capital, and political power in the evolved institutions correlates with geographic patterns of factor endowment (Sokoloff and Engerman, 2000).

Between 1501-1865, one estimate of the African population — mainly from West Africa—shipped to the Americas through the Atlantic slave trade is $10-15$ million people, with $6 \%$ accounted for by the 13 original colonies (Hughes and Cain, p.46, 2011). In the Northern colonies, 59\% of Black people were slaves, in the South, 95\% (Ibid.). The absence of premier crop territory in the Northern colonies encouraged more equal distributions of wealth and human capital, further, the extensive land and diminished capital requirements allowed a majority of male adults to be independent proprietors (Sokoloff and Engerman, p. 223, 2000). The lack of agricultural economy in the North inspired the beginning of industrialization in the 1700s, and shifted the already less labor dependent economy, farther away from that of the Southern colonies. The quality of the soil in the South imparted an increased significance on physical labor and an agricultural economy, severely impacting the notion of equal distribution and utilization of labor exploitation (Sokoloff and Engerman, 2000). It is not insignificant to note that until the Revolutionary War, the rule of the British Crown controlled the customs, legislation, citizenship, and 
social practices of the colonies ${ }^{24}$. Following the Revolutionary War and the independence from the British, the Missouri Compromise, and the Kansas-Nebraska Act marked legislative ground gained and lost by the movement to end slavery in America. The progress towards abolition through the Civil War and Emancipation Proclamation was followed by the destructive degeneration under Andrew Johnson's "Black Codes." The battle for Black people to gain respect or equality was fought for and against with tenacious aplomb. The passage of the 13th, 14th, and 15th Amendment was not by any means easily signed and regardless, left Black people as unequal members of society. Despite the strength within Black Communities, the perseverance displayed was not enough to earn the respect of white people in many cases.

The significance and depth of discriminatory inequality cannot be understated. Inequalities on the basis of race were integrated into the foundation of American systems and structures beginning in the era of the colonies. Characterization of the economic maturation in trade relations illustrates the transition from reliance on imports of finished manufactures to high exportation of finished manufactures, along with an increase in the importation of crude materials, which can be translated into finished manufactures production given production potential and progressive industrialization (Hughes and Cain, 2011). The role of cotton and Eli Whitney's innovation of the cotton gin in economic expansion and the propulsion of industrialization is extensive. The expanding production of cotton in the U.S. correlates to the import-export economic growth, in addition to expansion of the slave system and the exploitation of Black people (Sokoloff and Engerman, 2000; Bailey, 1973). The Civil War, while resulting in the Emancipation Proclamation, was not a war fought on the basis of racial equality, but rather the future and direction of growth for the American economy with emancipation of Southern slaves as a tertiary component (Downs, 2012). The victory of the Union Army over that of the Confederate in the South, was the resulting product of the advanced technology through Northern industrialization, and the contributions

\footnotetext{
${ }^{24}$ The initial population sent by Great Britain was composed of those free men (people seeking religious freedom and some independent settlers), indentured servants, redemptioners, prisoners, and slaves of the Crown. Per British rule, rights, levels of citizenship, eligibilities, and opportunities decreased respectively for individuals of each title, to the end of people being of the same classification as property (Hughes and Cain, 2011).
} 
of free Black folks and escaped slaves who fought as Union soldiers. Emancipation, while often considered the end of slavery in the United States, was reliant on the victory of the Union Army, riddled with exemptions, allowing the continuation of slavery, and those freed by the proclamation, were given nothing and nowhere to start establishing a life in the U.S. (U.S. National Archives, n.d.; Downs, 2012). The abolition of slavery and refusal to honor land distribution policies of the Freedmen's Bureau resulted in a new system of Black economic deprivation and exploitation, sharecropping (Bailey, 1973; Bindas, 2010). The economic opportunity and freedom experienced by people of color was essentially none, with debt-enforcement structures and shackling legislative limitations that would drive the establishment of infrastructurally racist ghettos (Downs, 2012; Bailey, 1973; Marable, 1983). Following the Civil War and regardless of the establishment of the Freedmen's Bureau, African Americans and Black people continued to be denied the rights of American citizenship, facing ongoing oppression and discrimination across the United States.

The failures in establishment of the healthcare system capture amplified examples of Black navigation through a contextually significant structure in the United States. The Freedmen's Bureau and the blatant discrimination, neglect, and abuse that people of color experienced at the hands of the system built to provide healthcare to the poor, sparked the authoring of books in the vein of Rebecca Lee Crumpler's "Book of Medical Discourses in Two Parts" (1883). The writings of Dr. Crumpler, who was an incredibly accomplished and trailblazing female lead in the medical field, further reinforced the fact that Black people, freed or not, would not be taken care of by U.S. government-created systems. Crumpler, wrote volumes that spoke not to her colleagues, but rather to Black households and Communities who would need her expertise, advice, and knowledge to be able to independently cope with and treat any ailments and illnesses they sustained. Dr. Crumpler's writings symbolize a clear, written record of the separation of Black people from the institutional and pseudo-systematic healthcare systems of the United States ${ }^{25}$. Later, Carter G. Woodson authored literature detailing and correcting the

\footnotetext{
${ }^{25}$ The phrase pseudo-systematic in regards to the national healthcare system in the time period is in reference to the establishment of healthcare institutions for the poor and people of color who did not have access to and could not afford the traditional physician home visits.
} 
popularized falsities about Black and African history and more directly encouraged Black people to 'do for themselves' and reiterating the notion that the systemically ignored must develop independently (Woodson, 1933). Through historic analysis, it is repeatedly illustrated that Black folks have been taken advantage of, neglected, and subjected to mistreatment in medicine and the healthcare system; the Tuskegee Syphilis Experiment, and exploitation of Henrietta Lacks to name a few of the countless examples of medical discrimination and abuse of Black people within medicine. The Black Panther Party (BPP) pioneered numerous programs aimed at systemic navigation and independent solutions for neglected Black Communities. In addition to programs like the Free Breakfast for School Children Program, the Black Panther Party established the Joseph Waddell People's Free Ambulance Service, People's Free Medical Clinics (PFMC), and the Sickle Cell Anemia Research Foundation (Bloom and Martin Jr., 2013; Nelson, 2011). The programs and services provided by the Panthers had an extensive impact on Black healthcare in the U.S. and exemplifies similar principles to Dr. Crumpler's work in the creation of self-sufficient structures to navigate the racially-selective American systems, including but not limited to the national healthcare system.

The Civil Rights Movement of the 1950s and 1960s illustrates the continued struggle for social justice for African Americans and equal rights under United States law. To this day, systemic and structural racially-based inequalities have not been rectified. Fundamentally racist ideology, legislation, and practices were not abated from the structures and systems that evolved in the United States. Opposed to the uncontested citizenship and rights endowed to white people, legislative crusades were required for all advancements in the legal acknowledgement of Black people and recognition of their rights being denied $^{26}$. Throughout the past four centuries any and every advancement for the rights and equality of minorities, specifically African American and Black people has resulted from standing up in the face of oppression and suffering with ultimate determination and commitment to achieve equal rights and treatment from the systems within the United States.

\footnotetext{
${ }^{26}$ Particularly significant legislative advancements of Civil Rights and the campaign against Jim Crow Laws; see Brown v. Board of Education of Topeka, Kansas (1954), Bailey v. Patterson (1962), Civil Rights Act (1964), Voting Rights Act (1965), Executive Order 11246 (1965).
} 


\section{Historic Moments of Tension and Dynamic Amplification}

It is undeniable that throughout United States history the inequality, discrimination, and oppression of minorities is thematic. Written in history textbooks are momentary nods to specific moments of resistance and perseverance, righteous determination, and heinous consequential punishment endured by African American and Black citizens as a result of their participation in movements for social change. Acknowledgement and awareness regarding the experience of African Americans and Black history at large is undoubtedly important and underdeveloped in American education systems, however; for this work, honing in on moments of extreme tension and unrest is fruitful to examine as points of amplification in social dynamics. Looking at points of civil unrest and the clashing of Communities with emergency service personnel, specifically moments of fire service involvement shed light onto the creation and expansion of the gap in relations seen today between fire service personnel and members of predominantly African American and Black Communities. Three moments of particular interest are the Birmingham Children's Crusade, the Watts Rebellion, and the Rodney King Rebellion. The city of Los Angeles provides a unique environment for examination in that the urban center has been the backdrop for several nationally-remembered demonstrations resulting from racial injustices perpetrated by police and the national campaign for Civil Rights and equitable treatment of Black and African American Communities.

\section{a. The Civil Rights Movement and the Birmingham Children's Crusade of 1963}

While the Civil Rights Movement expanded over a comparatively far more significant amount of time, there are key themes and patterns in the treatment of Black and African American activists throughout the most active decades of the movement. The Civil Rights Movement was most active through the 1950s and 1960s, with involvement and action taken across the United States. Some of the significant leaders and activists in the Civil Rights Movement include Dr. Martin Luther King Jr., Malcolm X, the Black Panther Party, Rosa Parks, John Lewis, Angela Davis, the Little Rock Nine, and 
Josephine Ruffin, to name a few. Within the highlighted decades of activism, there are multiple instances of civil rights demonstrations resulting in the use of fire hoses to subdue activists and demonstrators.

The Birmingham Children's Crusade ${ }^{27}$ (May 1963) was one event that received a large amount of media coverage and captured images and recordings of the forceful measures ordered by the Commissioner of Public Safety Theophilus Eugene "Bull" Connor in an attempt to end the peaceful demonstrations of young Black activists. At the time, Birmingham was one of the most segregated cities in the United States, with no movement to desegregate public spaces. Dr. Martin Luther King Jr., in partnership with the Southern Christian Leadership Conference (SCLC) and other activist groups, organized peaceful demonstrations. The first days of the protest resulted in hundreds of arrests, in an attempt to round up the participating body and drain the momentum from the demonstration. In the following days, with jails filled to near capacity, high school age and younger children carried the torch of the movement and were met with the orders of Commissioner Connor. The Commissioner specified the use of force in the way of attack dogs, police billy clubs, and high pressure fire hoses.

Police officers and firefighters were photographed in control of the weaponized equipment. In moments that police wielded the hoses, firefighters still acted in compliance with the Commissioner's orders and it was fire department equipment being used to inflict harm on the young activists. The use of fire hoses and the fire department's obedience to the violent and inhumane orders of the Commissioner presented firefighters and police officers in an image of unity and as a symbol of the brutality against peaceful African American and Black demonstrators. Davi Johnson provides an analysis of the images and commentary on the symbolism behind the actions taken, noting the reversal observed by the firefighters' actions and the utilization of "the very tools designed to protect the Community from threats of nature (fire) are turned into weapons turned against the citizenry" (Johnson, p. 10, 2007). Johnson references a news article from May 6th, 1963 that reads "Police had earlier sealed off Kelly Ingram Park where Negro mobs had gathered for the last several days to throw rocks, bottles and bricks at police and firemen. Negroes crowded the sidewalks in all directions, however. Firemen stood ready with high

\footnotetext{
${ }^{27}$ Also referred to as the Birmingham Campaign.
} 
pressure hoses to quell any outbreak of violence" (Johnson, p. 24, 2007). The framing of the actions taken by the activists indicates that there was an element of a pre-established reputational unity of the fire department as a pawn that worked with the police department and as a mechanism of oppressive United States systems. There is a succinct difference in the origin and evolution of the fire service and the police, however; the moment the fire department sent the message of compliance in the infliction of harm on the basis of the Commissioner's orders, was the moment that the Community—who was supposed to feel protected and served by the fire department — was obligated to reconsider the loyalty of the claim. Further, the actions and representation that the Birmingham Fire Department displayed, set the nationally viewed precedent for and symbol of fire departments across the country and specifically to African American and Black Communities across the United States.

The tensions and civil unrest at the injustice experienced by Black people across the country continued to mount to explosive heights. The summer of 1964, only days after the 'riots' in Harlem — the response to the death of an African American teenager, James Powell, at the hands of an off-duty police officer- on July 25th in Rochester, New York, during what would be remembered as the Rochester Rebellion or the Rochester Riot, police officers are pictured backing up firefighters as hoses are directed at 'rioters'. Three days later, another image is captured of a woman attempting to remain standing outside a residence while a heavy stream of water is pictured sweeping across the front porch of the home. The image captures police officers, with clubs in hand, menacingly standing and watching the woman struggle to stay on her feet outside the gate. The dynamic amplification of 1963 and 1964, specifically, the national portrayals of the weaponization of the fire department fostered further distrust of the fire department as an institution of the state and a complicit body in the state sanctioned oppression of Black people. A nationally covered display of Community distrust would take place in Los Angeles, California in 1965 during the Watts Rebellion, highlighting an additional perspective to the propagation of the relational gap. 


\section{b. The Watts Rebellion of 1965}

The examination and evaluation of the Watts Rebellion of 1965, reveals the distrust, resentment of the fire service, and perceived imposition of service on the primarily African American and Black Community. The relations between firefighters and Community members are elucidated by the dynamic magnification of Watts. The Watts Rebellion ${ }^{28}$, titled after the borough of Los Angeles in which the civil disturbances occurred, was a Community response to the altercation between police officers and the Frye brothers. Watts and the South Central region of Los Angeles, historically low-SES areas of the city, were and are predominantly populated by African Americans demographics (Warheit and Quarantelli, 1969; U.S. Census Data, 2020). Prior to the Watts Rebellion, fire department data and statistics illustrated that Battalions 13 and 8 - those providing service to the regions - reported the highest number of fires of any battalions in the city. Census data also indicated that Watts was significantly more overcrowded than the average persons per household figure for the city overall (Warheit and Quarantelli, 1969). On Wednesday, August 11th 1965, a California highway patrol officer pulled over Marquette and Ronald Frye in the Watts district of Los Angeles prompted by suspicion of an intoxicated driver. The attempted arrest of Marquette escalated the incident and drew a crowd from the Community, in addition to a request for backup law enforcement units to respond to the scene. Resulting from the use of force, causation in the arrests of the Frye brothers and their mother — who had later arrived on scene — and the tactics employed by highway patrol officers to control the crowd, the already volatile situation between law enforcement and members of the Watts Community rapidly intensified. The initial scene of the arrest concluded with the stoning of a police unit and the organization of small groups of Community members who patrolled the streets, stoned vehicles, and beat white drivers in the area (Warheit and Quarantelli, 1969).

\footnotetext{
${ }^{28}$ Also referred to as the Watts Riots, were highlighted in exceedingly negative light through multiple portrayals and recounts in the media, see (Cammarata, 2018). News coverage and much of the literature focused on the events uses terminology of 'rioters', 'mob', 'unruly', etc. The use of this terminology can be problematic in the recounting of this Rebellion and demonstrations like it, as the exceedingly negative connotation of those terms fails to acknowledge the progress that these acts represented within the Black Communities.
} 
The first two initiations of the Los Angeles Fire Department (LAFD) response occurred early Thursday morning. Upon arrival at the incident scenes ${ }^{29}$ firefighters were met with missiles and debris (Warheit and Quarantelli, 1969; Governor's Commission on the Los Angeles Riots $\left.{ }^{30}, 1965\right)$. The same evening, following a meeting between the County Human Relations Committee, Black Community leaders, and representatives of neighborhood groups, LAFD apparatus was dispatched to the area in response to reports of overturned vehicle fires. Arriving crews were pelted with rocks and shot at, later being forced to abandon apparatus on the scene by increasing gunfire and missiles targeted at firefighters (Warheit and Quarantelli, p.17, 1969). Police were dispatched to conduct crowd control at the first structure fire set during the demonstrations at 10:46 p.m., to allow firefighters to extinguish the flames. Several additional large structure fires were set in the early hours of Friday (August 13th) and five hundred police officers were assigned to gain control of the demonstrators. Disturbances and looting took place throughout Watts and neighboring areas, and patterned commercial fires were set in areas that extended into Los Angeles County and the city of Compton (Warheit and Quarantelli, p. 17, 1969). Fire crews were withdrawn from fire incidents as a result of insufficient police protection and staged until law enforcement established control of the scenes. Assistance from the National Guard was requested and assembled by Friday evening.

The most severe point in the Rebellion occurred the evening of the 13th and extended into Saturday morning (August 14th) after the first fatality of the demonstrations took place in an escalation of gunfire exchanged between police and demonstrators (Warheit and Quarantelli, p.18, 1969). The shootout's victim was a Black bystander. The death of the Black civilian sparked a spree of fires set throughout the area requiring 100 engine companies and 26 ladder trucks of the LAFD and Los Angeles County Fire Department (LACoFD) (Governor's Commission on the Los Angeles Riots, 1965). The National Guard and police coordinated an effort to allow the fire department to fight the numerous unattended fires. A curfew was imposed by the Lt. Governor in an attempt to gain control of the 32.5

\footnotetext{
${ }^{29}$ The two calls for fire department response were one automobile fire set by demonstrators and one routine service call.

${ }^{30}$ Also known and referred to as the McCone Report, see McCone and Christopher (1965).
} 
square miles that covered the Watts area within the Los Angeles city limits (Warheit and Quarantelli, p. 18, 1969). Military, police, and fire services were the only groups legally allowed to be out past 8:00p.m. The last major disturbance resulted in fire crews forced to evacuate their positions of fire control and extinguishment — referred to as fire attack positions within the fire service — and the scene of fire devastation three times to evade sniper fire. The exchange of gunfire between the snipers, police, and the National Guard served as the end of the critical disturbances in the Rebellion.

The Frye arrests by white law enforcement officers occurred during a very climactic period in the Civil Rights Movement, racial tensions across the country were unstable and eruptive in the fight for desegregation and equal rights for Black and African American people. The following three days of turmoil brought national public attention to the continued tension and violence between African American Communities and primarily white military, police, and fire service personnel (Cammarata, 2018). It is estimated that 2,000 fires were set over the course of the Rebellion, with responding firefighters frequently bombarded by Molotov cocktails and stones (Reeves, p.39, 1980). The Rebellion resulted in 1,032 injured people, 34 fatalities, 31 of which were deaths of Black folks shot by police or military. 773 of the 1,032 injuries were civilians, 132 accounted for firefighters, 90 L.A. police officers, and 10 members of the National Guard (Warheit and Quarantelli, p.19, 1969). From the 132 firefighter injuries, 32 were inflicted by demonstrators, four of which resulted from gunshots. A total of 114 injuries were gunshot wounds (Warheit and Quarantelli, p.19 1969). The property damage from the three days of violent demonstration was estimated at 40 million dollars, with over 600 buildings significantly damaged, more than 200 of which were totally destroyed by fires (Governor's Commission on the Los Angeles Riots, 1965).

The observed response of demonstrators to the presence of firefighters during the Watts Rebellion speaks loudly to the perception of the fire department within the body of activists and in detangling the magnitude of amplification, indicates the perception of the overarching Community. Broadening and refocusing the lens on the Watts Rebellion to capture the larger context of the Civil Rights Movement and the demonstrated weaponization of the fire department, the violence directed at firefighters during the 
Watts Rebellion can serve as a proxy for the response of the nationally impacted Black Communities. Momentum of Civil Rights demonstrations maintained through the remainder of the 1960s and into the 1970s. Two years following the Watts Rebellion, the Long, Hot Summer of 1967 encapsulated civil unrest that resulted in 159 demonstrations across the country. In addition to the loss of life, thousands of injuries, and millions of dollars of infrastructural damage, the demonstrations resulted in the establishment of the Kerner Commission ${ }^{31}$ — though the report and recommendations following the Commission's investigation into the widespread civil unrest that occurred throughout the 1967 summer was ignored by President Johnson, who opted to compound the issue at the core of the racial tensions through the increase in police funding by the LEAA (Reeves, 1980; Lyons, 1976; Kerner, 1968). The city of Los Angeles would later serve as the territory of origin for a larger demonstration in the wake of the jury acquittal of Los Angeles Police Department (LAPD) officers charged for the beating of Rodney King in 1992.

\section{c. 1992 Los Angeles Uprising — The Rodney King Rebellion}

In 1992, South Central Los Angeles again broke out in civil unrest in response to the videotaped beating of Rodney King. The acquittal of four members of the LAPD charged with excessive force in the arrest of Rodney King ignited nearly a week of outrage and response, leading to demonstrations that dwarfed those of the Watts Rebellion (Evans, p.267, 1993). Preceded by a high-speed motor vehicle chase, officers were recorded repeatedly tasering and brutally beating King until inflicted injuries rendered him unable to get up, at which point he was "handcuffed and dragged to the side of the street" (Solomon, p. 25, 2004. King's injuries included nerve damage, broken bones, skull fractures, and permanent brain damage. The demonstrations had infrastructurally halting impacts on the city of Los Angeles, including the lost electricity, suspended transportation, and safety concerns for Community-based essential workers (Evans, p.266, 1993). Deployment of the National Guard and preparation of Marine and Army units, along with enforced curfews were some of the measures taken in an attempt to gain control over the civil disturbances. Statistics from the Uprising report 53 fatalities,

\footnotetext{
${ }^{31}$ See (Kerner, 1968) for the originally published Kerner Report.
} 
more than 2,300 injuries, of which 248 were hospitalized (Evans, p.265, 1993). Among these statistics, 54 firefighters and EMS personnel were injured, including Captain Scott Miller who survived being shot in the neck. Over 600 buildings were completely destroyed and estimated property damage is over $\$ 1$ billion (Webster, 1992). The fire department received over 5,500 calls for response and required 2,700 firefighters over the course of the demonstration (Johnson et al., 1992). Gunfire was used to prevent firefighters from extinguishing blazes and was directed at apparatus driving in the area. Black Community leaders and the McCone report had previously warned and predicted demonstration escalation without serious intervention in the urban issues facing Black Communities and structural practices of law enforcement personnel.

The Rodney King Rebellion additionally illustrates the relationship between Black Community members and fire service personnel. The case study of the Rodney King Rebellion further supports that the observed interactions and dynamics during the Watts Rebellion was not an isolated event and that the severe damage done to Community perceptions and relations was not rectified or healed after the initial events and structural creation of the relational gap between firefighters and low-SES, Black Communities.

Much of the sentiment in Black communities, expressed in regards to the 1960s, though not confined or developed in that era, was there any government institution, or public service was not equally provided nor created for Black people. This foundational inequality cannot be summed into the particular magnification of the Birmingham Children's Crusade of 1963, Rochester New York's Rebellion, or the Watts Rebellion of 1965, however, these distinct national moments serve as a lens through which the fire service is currently evaluated by Communities and as a critical component in the institutional methodologies and considerations for the development of the fire service in the future.

\section{Literature Review and Quantitative Commentary}

\section{A. Considerations in Assessing Utilization and Provisional Equity}

Quantitative statistical analysis and a review of fire and EMS utilization data speaks in volumes for the passion and continued embodiment of fire service foundational core values. However, before 
commenting on the collected statistics and data, underlying structures correlated with and contributing to the observed patterns of utilization must be acknowledged and considered. Particularly in regards to provisional equity, factors that contribute to utilization of fire and EMS are rooted in fundamental systemic racism and classism that subject low-SES and Black Communities to increased environmental hazards and disproportionate obstacles to attain medical services. Contributors to the patterns in emergency dispatch of fire and EMS are considered and utilized to situate fire and EMS statistics through the illustration that depicts low-SES and Black Communities constructed on principles to increase the reliance on emergency services and mandate the disproportionate utilization of fire and EMS.

\section{a. Fire Risk and Socioeconomic Status}

The increased risk of fire associated with low-SES Communities, has to be considered through the framework of the ghettoization and inflicted intergenerational poverty on Black Communities. There are numerous factors that contribute to the increased risk of fire in low-SES Communities, including the combustion potential and flammability of building materials, the level of investment in neighborhood maintenance, and the population demographics often associated with overcrowding in residential occupancies (Quarantelli, 2000; Jennings, 2013; Smith et al., 2008). The work of Charles Jennings illustrates the fire risk associated with social and economic characteristics (Jennings, 1999; Jennings, 1997; Jennings, 2013). The increased risk of fire in low-SES neighborhoods serves as not only a danger to the health and safety of individuals living in the Communities, but as a marker for inequality across urban areas in the level of governmental investment and success of fire safety education (Kuswa, 2002; Hastie, 2014). Low-SES and Black Communities have a level of distrust associated with institutions of the state, including medical services and the fire service which only further propels and exaggerates the inequalities and disparities in quality of life for Community members (Hastie, 2014; Nelson, 2011; Marable, 2011). While not solely focused on Black Communities, the sequestration of Black folks into poorly maintained, low-SES neighborhoods indicates specific targeting of racist geographic practices and infrastructure that results in Black Communities existing in urban boroughs with higher risks of fire, fire related injuries and 
death, and generally increased exposure to environmental hazards (Jennings 2013; Jennings, 1997; Kuswa, 2002). The environmental hazards and racist infrastructure that results in low-SES and Black Communities being exposed to disproportionate levels of risk is undoubtedly correlated with the increased activation of the 9-1-1 system for fires in those Communities. Dispatch of the fire department for emergencies that involve actually fighting fires, however, is no longer the most prominent aspect of the fire department or most frequent type of call. In many departments across the country, firefighters are required to have the EMT license - if not their paramedic license - enabling response for medical emergencies, even if the municipal ambulance and EMS is provided by a contracted private company. Today, medical emergencies are the most frequent call type received by the fire department and therefore, the patterns of utilization of the EMS system is also a significant indicator and point of analysis in provisional equity.

\section{b. Utilization of EMS \& Social Determinants of Health}

The utilization of EMS serves as not only a reflection of the geographic and spatial limitations and restrictions regarding accessability of low-SES and Communnities of color to healthcare facilities, but also illustrates the ramifications of medical discrimination, neglect, and abuse that Black folks have experienced throughout U.S. history ${ }^{32}$. EMS providers are often dispatched and utilized as healthcare providers for treatment and care of chronic illnesses and conditions that should be overseen by physicians and general practitioners. Similarly to the utilization of EMS and the fire service, analysis of relations and present-day interactions between Black people and medical services is incredibly important and must be considered through recognition of systemic racism and the historical significance (Evans and Gusmano, 2021). Accessibility for Communities of color and low-SES Communities is a quintessential component in the analysis of provisional equity, not only in fire and EMS, but the provision of medical care at large. Without the accessibility to and generalized inclusion of Black and poor people in receiving healthcare

${ }^{32}$ See (Bentley, 2017) for history of the Freedmen's Bureau, (Washington, 2006) to elucidate medical experimentation and abuse that Black people have suffered at the hands of medical practitioners. 
and medical treatment, many poor folks and people of color rely on the care of emergency first responders in the role of a general physician or nurse practitioner, which increases the concentration of 9-1-1 calls to fire departments and EMS (Adio et al., 2020; Knowlton et al., 2013). Another perspective addresses the hesitation and resistance to calling 9-1-1 unless a situation is catastrophically dire to the patients or bystanders (Rucker, et al., 1997; Shah, 2008; Smith et al., 2008). From the reported data, there is a correlation between the mentality of utilization and age, with middle-aged Black men being the most frequent callers of 9-1-1 (Rucker et al, 2005; Adio et al., 2020; Knowlton et al., 2013). There is no obfuscation regarding the health disparities or the repercussions resultant of the oppression that Black and poor people face and experience, which leaves folks with a larger propensity for several chronic conditions, serious illnesses and diseases, and a higher risk of sudden health complications. David Williams and Pamela Jackson address the impact of race and socioeconomic status on health in their work (Williams and Jackson, 2005).

In 1968, "the surge in fires that occurred in the late-1960s associated with racial unrest, urban economic decline, and notable high-profile fires" influenced the passage of the Fire Research Safety Act (FRSA) (Reeves, 1980). With the signing of the bill came funding for research into the fire service and fire risk. "A negative relationship between socioeconomic status and fire incidence was observed. Areas with low socioeconomic status had higher incidence of fires. These areas were classified according to fire incidence, and the patterns were preserved." (Jennings, 2013). Further, there is data regarding call volume in low-SES areas and demographics of callers for medical emergencies. Knowlton et al. demonstrated that a significantly correlated factor in the frequency of calling 9-1-1 is race, specifically African American demographics and low-SES Communities (Knowlton et al., 2013). There are a number of other studies that cite increased utilization of emergency medical services by low-SES Communities and people of color (Rucker, et al., 1997; Adio et al., 2020; Alter, Stukel, and Chong, 2011; Corcoran et al. 2007). Particularly, individuals without insurance and populations who are excluded from access to healthcare, utilization of emergency medical services system consists of two main ideological models of 9-1-1 activation. Aversion to 9-1-1 activation until an ailment or injury has progressed to an extent that has 
become critical and imperative of immediate medical intervention. Alternatively, yet simultaneously, the utilization of ambulance services for general medical needs. "Specific chronic somatic conditions that are escalating in prevalence and healthcare costs, and disproportionately affect African Americans, the majority of the Baltimore population, were also main contributors to frequent use of the city's EMS system. Two-fifths of frequent EMS users had indications of diabetes and of asthma, and almost one-tenth had HIV/AIDS" (Knowlton et al., 2013). The disproportionate call volume in low-SES Communities and Communities of color make a statement beyond the provision of emergency services and extends to the interconnectedness of systemic disadvantage. "The early research efforts conclusively established that fire incidence varies systematically according to social and economic characteristics of residents, and secondarily by housing and neighborhood conditions." (Jennings, 2013). The increased risk of fires is correlated with implications for public health and disparities in the social determinants of health. Jennings cites Wallace and Wallace's theoretization that a self-reinforcing cycle of dilapidation and increasing fire risk will result without management of social conditions in low-SES Communities (Jennings, 2013). Many health conditions and the severity of illnesses can be proactively mitigated or treated before progressing to a point of being emergent, however; it is the lack of access to care and trust of the medical field that impedes and excludes low-SES and Black Communities from receiving preventative medicine and routine check-ups. Reliant on geospatial and economic factors as well as trust in practitioners, Community-based programs have the potential to decrease the amount of health disparities experienced by low-SES and Black Communities and therefore, decrease the disproportionate reliance on emergency medicine (Adio et al., 2020; Kennedy et al., 2007).

Economic and geospatial aspects contribute significantly to the patterns observed in the utilization of fire and EMS, but there is a paramount factor that carries enough weight to maintain the patterns observed, even if other components were addressed: trust in medical personnel and practitioners (Kennedy and Mathis, 2007). As discussed, United States history is riddled with atrocious instances of neglect and abuse, a few of the most prominent nationally recognized demonstrations of this mistreatment include the Freedmen's Bureau, the Tuskegee Syphilis Experiment, and the exploitation of Henrietta 
Lacks (Bentley, 2017; Evans and Gusmano, 2021; Skloot, 2017). The significance of trust in medical practitioners cannot be understated in the context of healthcare equity (Cruess, 2008). Further, the atrocities do more than explain and justify the distrust that Black folks have towards the medical field and the generational distance that has been established between Black Communities and the healthcare system (Washington, 2006; Evans and Gusmano, 2021; Jacobs et al., 2006; Thomas and Casper, 2019).

Research and equality evaluation in the United Kingdom (UK) has drawn conclusions and patterns similarly to what is observed in the United States. Assessments of risk indicate that low-SES Communities correspond to the regions with the highest instance of fire and where patterns of state institution distrust are reported (Clarke and Kaleem, 2010; Hastie, 2014). Yet, through objective and quantitative data analysis, the provision of services by the fire department and EMS is equal across all Communities in the fire departments that have been examined. These findings and conclusions demonstrate that the foundational core of the fire department maintains significance and relevance to modern fire service provision, but that there is a piece missing in the communication and narratives of fire department personnel who believe in equitable provision of service and Community members who don't feel equitably served, lack trust of governmental institutions, and are disproportionately reliant on fire and emergency medical services.

\section{B. Firefighter Perspectives on Fire Department Weaponization and Importance of Community Trust}

Following the events of September 11th, 2001 (9/11), a series of interviews were conducted by 'Fire Engineering' staff members of several fire chiefs and personnel from across the country, specifically highlighting their answers to a question asked about the weaponization of the fire department and a statement released by the IAFC. Eleven fire chiefs, lieutenants, and company officers were interviewed from eleven states and asked the same question: "The International Association of Fire Chiefs (IAFC) recently issued a statement voicing its objections to the "use of firefighter or other rescue personnel, their uniforms or likeness thereof, or fire apparatus to gain an advantage in criminal action by law enforcement 
representatives." The IAFC executive director noted that such activities "violate our public trust" and create hazards for our personnel by "compromising our ability to operate in hostile situations." There have been instances in which firefighters have been requested by local government officials to hose down crowds of unruly people or when law enforcement officers have proposed dressing as firefighters while carrying out police-related duties. Has your department ever received such a request?” (F.E. Staff, 2001). Each fire service member responded with the same sentiment, that the fire service operated successfully with the trust of the people the department is tasked to serve and breaching that trust would be effectively destroying the trust that had been particularly magnified following the response to $9 / 11$ and the 343 firefighters that perished in the collapse of the towers - not to mention the countless others who would die from complications following the exposure to physiologically devastating toxic chemicals at Ground Zero. Again, the tone of heroism and bravery was a national rhetoric and cannot be assumed as universally shared, however, there was a national respect for the individuals who ran towards the most devastating event in modern American history.

The tone reiterated by all of those interviewed highlighted a very clear distinction between fire service personnel and law enforcement, and while acknowledging the required cooperation between the two departments, each fire service member stated the necessary separation and strict boundary in the level of aid the fire department would be willing to provide law enforcement officers. This sentiment is something that is largely shared throughout the country. There were three interviewees who specifically brought up the events of the 1960s and referenced the disturbing history of fire service alignment with the police department and governmental orders to aid in the control of civic action. The response of Battalion Chief G. Moose Barkdull of the West Valley City Fire Department in Utah included the recount of a departmental battalion chief in the 1980s who was asked, pressured, ordered, and threatened with arrest for "failure to obey a lawful order" by police if he did not comply and "drown" the crowd during an event that escalated into what was deemed a riot (F.E. Staff, 2001).

In addition to a shared agreement with the IAFC and objection to the weaponization of the fire department in response to civil unrest, there was a displayed awareness in the interviewees' responses of 
the importance of trust and Community perception. However, even the interviews responses that specifically highlighted the 1960s and the events of Birmingham, and stated their department's policy of opposing requests by police for fire department aid in events of civil unrest, the historic events were isolated and separated from their own fire department, simply through their response to the question and position on the topic. The steadfast refusal of the fire department to engage in law enforcement requests for implementing fire hoses as a method of crowd control further supports the argument that the fire department's core as a Community service remains intact. However, it also speaks to the point that there is a standing contradiction between the significance of historical narratives and the protocols, beliefs, and statistics of firefighters and departments across the country. This contradiction points to a generalized lack of awareness and understanding that while the events of Birmingham, Selma, and Rochester were not perpetrated by the firefighters and fire departments that were represented in the interviews, for example, the significance of those moments to Black Communities was felt throughout the United States as a national symbol of fire department service provision conditionality. Explicitly, that the events were not isolated to the specific firefighters and fire departments that were responsible for the allowance of the fire department to be weaponized, and long before that the historically fundamental distrust of institutions imposed on Communities by the state. There must be recognition that the hegemonic narrative of heroism was only shared throughout the Communities that have felt historically served by the fire department. While the firefighters who run towards disaster gains the respect of people throughout the country, there is a lack of trust that firefighters would do that for all Communities experiencing catastrophic emergencies. A trust issue that must be addressed and mitigated on a local level by fire departments throughout the United States.

\section{Quantitative Data}

Disproportionate state investment in low-SES and Black Communities increases the reliance on fire and emergency medical services through systemically reinforced factors of geographic and economic racism and disparities in the social determinants of health that results in increased fire risk, exposure to 
hazards, and utilization of emergency medical services. Today, fire departments spend the majority of their time and call volume dedicated to medical emergencies, car accidents, and any miscellaneous public hazards. While fighting fires is no longer the isolated purpose of the fire department - making up between $10 \%-30 \%$ of overall call volume - the instance of structure fires is a primary measure of analyzing the utility, usage, and strain on fire departments ${ }^{33}$. Quantitative analysis of provisional equity of fire and emergency medical services can be analyzed from fire department and EMS data across three specific factors. Call volume, station distribution through GIS mapping, and response times. Call volume or call density represents the call concentration across specific FMAs within a department. These call concentrations can be mapped against population demographics of socioeconomic status and race to determine where there is the most need for fire and EMS. Data from fire departments across the country demonstrates low-SES and Communities of color correlate with the neighborhoods and FMAs that report the highest call density.

There are two primary models regarding the placement and distribution of fire stations across urban areas. Two schools of thought have historically influenced the debate and conversation. One in which each station is placed in the most Euclidean-based efficient locations; highlighting geospatial equidistance and theoretically creating virtually identical response times for calls throughout a given fire management area (FMA). The second model emphasizes concentrating resources, apparatus, and personnel in the areas of high call density (Beaumont, 1981). This system serves some people more quickly than others based on the concentration of calls and density of the population inhabiting the area. The model more significantly weighted and employed within different fire departments depends on several factors including amount of funding received for the provision of emergency services—based largely on the collected taxes for a municipality, the density of the population and the region or area across which fire departments are responsible for providing services (Getz, 1979; see Beaumont, 1981 for

\footnotetext{
${ }^{33}$ This is largely a result of the varying structures of emergency services organization by city. Fire departments, whether solely responsible for the provision of emergency medical services or not, will serve as the only emergency service required and often dispatched to intervene in fire emergencies.
} 
a review of mapping methodologies) ${ }^{34}$. While there have been several methodologies for analysis, multiple regression has demonstrated to be the most significant measurement and explanation for the fire response rate variation (Jennings, 2013). The econometric analysis of multiple regression allows for any number of variables to be mathematically assigned a level of significance for the greater outcome. In Brisbane, Australia, the Floating Catchment Analysis (FCA) method was employed to measure the spatial accessibility of public services and translate the data into commentary on areas of inadequate accessibility with suggestions for improvements and advancements in the dispersion of fire stations in the present and the future (Kiran et al., 2020). The observed trend in literature and national data demonstrates resource allocation to provide equitable dispersion of fire stations to serve the majority of the population in any given fire department area. In urban areas, distribution of fire services has been evolving with the advisement of modeling system publications of different varieties based on technological advancements in geographic information systems (GIS). The algorithms that have been created factor in equity, call density, efficiency, and population to generate data on the optimisation of emergency response for all areas of an urban population (Beaumont, 1981; Gomersall, 2003).

The third factor in the analysis of provisional equality of the fire service and EMS is response times to incidents, regardless of location within an FMA. Analysis of first- and second- in fire companies are strongly correlated with GIS resource allocation and are standard in fire department review of efficiency and quality of service provided throughout a department. Fire departments annually release public reports outlining continuously tracked statistics of response times, call types, and call distributions, resulting in unobstructed data to review and the visualization of service provision. Statistics reported-in fire department data and the very few academic investigations of fire department service provision - demonstrate no variation in response times on the basis of population demographics or neighborhood boundaries (LAFD, n.d.; Gomersall, 2003). The review of station mapping analytics illustrates the evolution of fire departments alongside the growth and development of the cities they serve.

\footnotetext{
${ }^{34}$ Rural fire departments (largely when paid, but occasionally volunteer as well) often cross staff engine and truck companies, with an additional medic unit (ambulance) dedicated to medical services first but is staffed with trained firefighters who serve as operational fire crews when the station is dispatched to a fire.
} 
Station placement and the allocation of resources both indicate the distribution of fire apparatus based on the areas with the most need and highest call concentration.

\section{A. The Los Angeles Fire Department - Model of Provision Visualization}

Los Angeles County (LACo) encompasses 88 cities and $~ 140$ unincorporated areas of the City of Los Angeles (L.A. County, 2018). Appendix A, Figure I illustrates the geographical boundaries for each Community. Figure 2 offers the map of Los Angeles Fire Department (LAFD) Battalion boundaries. In the 88 cities and 140 unincorporated areas within the City of Los Angeles there are two options for the provision of fire and emergency services. The municipality can either choose to establish its own department — either volunteer or paid, or LACo Fire Department (LACoFD) can be commissioned to staff or continue staffing the stations already positioned within the district ${ }^{35}$. In the case of Compton, for example, the Compton Fire Department (CFD) was established with 4 stations, 84 full time firefighters, and while maintaining one of the top 5 busiest stations in the state of California, the average CFD response time is 4 minutes and 30 seconds - a particularly efficient and notable standard (Compton F.D., n.d.). Figure 3 and Figure 4 offer the geographic concentration of income and African American population throughout a specific section of Los Angeles. Call distribution data was collected from the Los Angeles Fire Department (LAFD) and compared to the median household income data reported (see Fig. 3) in Figure 5. The same procedure was performed with the Census data reporting the distribution of the African American population (see Fig. 4) to generate the comparative map in Figure 6. The illustrated data demonstrates the relationships that the scholars cited in this work have verified, even though the use of Census data is less accurate and efficient in the reporting of specific variables that contribute to the increased risk and utilization of low-SES Communities. While factors that lead to higher call volumes in poor, and in this case, predominantly African American populated Communities, are not explicitly demonstrated, demographic correlations are observable. Beyond the utilization visualization of fire and EMS in Los Angeles created by the maps in Appendix A, the LAFD publically features a data tracking

\footnotetext{
${ }^{35}$ See (Getz, 1979) for economics of an urban fire department.
} 
tool on their website that archives data — the same data the department uses for evaluation — and provides live tracking of LAFD calls and response.

From the start, an interesting pattern of the municipalities encompassed by Los Angeles County and the demographics in the regions just outside of the LAFD battalion boundaries is noticed. While there is an illustrated correlation, regression analyses are needed to make statements regarding the validity of the relationship observed and that further elucidate the amount of significance that income and racial demographics have on call volume and maps created to visualize concentration of call types in relation to Los Angeles City limits. Additional studies are also needed to make claims about specific response time and the equity in provision of emergency services in these areas, that would have to take into account the mutual aid between LAFD, LACoFD, and the fire departments contained in the municipalities. The pattern of boundary lines of the LAFD and Los Angeles City limits needs significant research and analysis to speak about any discriminatory exclusion that results from the historical development and jurisdictional technicalities. There is no data that suggests distribution of the fire stations in the Los Angeles Fire Department is inequitable. Response times do not indicate a significant or inequitable variation between Communities or regions of the city. Further, the publicly accessible, live and continuously updated statistical archive featured on the LAFD website allows for the general populous to review the equality of fire and EMS provision by the LAFD. This model of transparency is paramount and provides Communities with the opportunity to visualize the provision of fire and EMS in their cities and neighborhoods.

\section{Discussion}

Components of inequity extending beyond history in this field are also related to urban waterways and accessible water pressure for firefighters when arriving to extinguish a structural blaze, accessibility of residents from low SES Communities to personal vehicles, distance from hospitals and urgent care institutions, and neighborhood condition overall (Jennings, 1999; Kuswa, 2002). Urban development, infrastructural racism, and ghettoization of Black Communities resulted in intergenerational poverty in the 
United States, consolidation of Black Communities into largely isolated and poorly maintained areas, and unequivocally increased hazards to livelihood—including risk of fire (Kuswa, 2002; Bailey, 1973; Jennings, 1999). Scholars including; Knowlton, Rucker, Burstin, O’Neil, \& Brennan, Adio, Ikuma, \& Wiley, and Alter, Stukel, \& Chong, demonstrate that the disproportionate hazards experienced by low-SES and Black Communities extends into medical disadvantages and increased utilization of emergency medical services ${ }^{36}$. Fire departments across the country and globe track statistics of fire incidents, call volume, and the geographic distribution of emergencies. Comparison of emergency call distribution and factors of race and socioeconomic demographics ${ }^{37}$ reaffirm what fire departments are already aware of; that there is an increased need for fire and emergency medical services in low-SES and Communities of color. This statistical observation must be partnered with initiatives and communication between fire department personnel and Community leaders who are collectively aware of the existing relational dynamic between fire and EMS personnel and members of low-SES Black Communities.

Historical exclusion reinforced the need for the auto-annexation and creation of independent solutions in Black Communities (Smith, 2005; Marable, 2011; Bloom and Martin, 2013). The actions and complicit endorsement of Black oppression demonstrated by members of the fire service during the Civil Rights Movement further compounded distrust of governmental systems and emergency services. Repercussions of the violence during the Birmingham Children's Crusade and nationally witnessed symbolic transformation of the fire department from a service provided for the benefit and wellbeing of all Community members to a representation of another cog in the United States systemic oppression of Black people, deeply damaged the present and future fire department Community relations (Johnson, 2007). The actions of firefighters depicted in the images not only set the fire service back and diminished the mission, values, and purpose of the institution, but further made a nationally transmitted statement that if given orders, the health and protection of Community members would become a lower or momentarily nonexistent priority to the on-duty firefighters. The complicit actions and outright participation in the

\footnotetext{
${ }^{36}$ Citations for reviewed work by these authors are listed in References.

${ }^{37}$ See Appendix A for example provision visualization of Los Angeles and the LAFD.
} 
infliction of harm inherently called into question the very definition of service and the qualifications that Community members must meet to be protected under that definition. With the precedent set of a governmentally overseen — and controllable by public officials outside of the fire service - fire department, the reputational shift from being a service with a sole commitment to protecting Community and serving Community became a symbol that represented the infliction of harm on Community members under the orders of government administrators (Johnson, 2007). While there is a level of necessary and required cooperation between police and fire for the coordination of emergency response, the alignment that firefighters displayed with a system and pattern of brutality and oppression did immense damage to the trust and faith that Black and African American Community members could have in the fire service. Further, the actions observed in the Birmingham Children's Crusade by the BFD, for example, directly contradicts the foundational sentiment and beliefs of firefighters across the country. There is a respect for the work and commitment that firefighters display when they run into burning buildings, what's missing is the trust of the Communities they serve. Interviews conducted with members of the fire service following 9/11 highlight the shared opposition to firefighter involvement in police actions and the persistence of foundational beliefs that define service of the fire department, but that are not trusted by Communities (F.E. Staff, 2001; Hastie, 2014). The distrust of fire service personnel and damage to the relationship between Black Community members and firefighters would be further illustrated in subsequent years, with particular amplification of the Watts Rebellion and Rodney King Rebellion.

The Watts Rebellion and the rejection of fire service response is one of the most pertinent illustrations of the loss of trust in and resentment towards fire service personnel. Situational service provision resulted in further entanglement of firefighters with police officers, and propagated the relational gap between low-SES Black Community members and the fire department. Response to emergencies has been a concept of conditionality in these Communities. Fire department presence, without consultation of Community leaders or precursory effort to establish rapport with Community 
members, was viewed as an imposition of service, rather than a requested one ${ }^{38}$. Fire department response following the nationally broadcasted images and actions of firefighters was presumptuous and failed to acknowledge the impact that the preceding oppressive and traumatic actions had on the character and reputability of firefighters at large in the eyes of Black Communities.

Growth in the fire service scope of practice has shaped and reshaped the job description of being a firefighter, but the core value of providing service to the Community underlies the expansion in responsibilities. Services provided by the fire department were not built with a principle of conditionality. This is a fundamental understanding built into firefighters and departments across the country, that fire service personnel embody and is a reputation that local firefighters are responsible for maintaining in the eyes of the Communities they serve. Gomersall's explication reveals what I have experienced as well, that quantitative provision and commitment to response does not vary across socioeconomic boundaries or Community demographics (Gomersall, 2003; LAFD, n.d.). Statistical, spatial, and quantitative provisional equity is exceedingly important, however, the fire service at large and overall provision of service is not and cannot be considered fully equitable until the trust and acceptance of all Communities has been restored. The loss of trust and prominent display of reputational flux is not solely resultant of the captured actions of fire departments in the 1960s. Historic governmental affiliation and structures that bind the fire department to institutions founded on racism and oppression of African Americans necessarily lays the foundation for Black uneasiness and reservations of fire service personnel. As a targeted Community for systemic violence and oppression, awareness and resistance of governmental structures becomes a crucial component in the endeavor for personal, familial, and communal safety. Community relations with fire departments are determined by local interaction, however the development of national symbolism necessitates local recognition and intervention.

Images that to some represent distinctly isolated reprehensible actions of specific firefighters and departments, moments of institutional disgrace during a time of civil unrest, are the same images that

\footnotetext{
${ }^{38}$ Throughout the Watts Rebellion calls and requests for fire department (LAFD) response were not solely or even a majority of the time initiated by Community members. Much of the dispatch of fire crews was requested by police officers reporting status and condition, or from non-participating passer-bys.
} 
trigger visceral remembrance and generationally inherited trauma to Black Communities (Johnson, 2007).

Crucial to lessening of the relational gap is wide-spread consideration of positionality in regards to recollection of the photographed events through a distanced historical lens or as a memory of an affront on one's Community heritage and an unjustifiable rejection of personal identity ${ }^{39}$. It is critical to acknowledge the gravity and institutional repercussions resulting from national symbolism of violence and Community harm at the hands of the fire department - regardless of the locality initials printed on the helmets and turnouts ${ }^{40}$. Unrecognized privilege contained within the perspective of an institution or individual fosters pernicious distancing and conscious separation from historic events ${ }^{41}$. Aforementioned, improvement of local fire department relations with Black Communities requires acknowledgement and active intervention to align contradictory national narratives.

The actions during the Watts Rebellion and targeting of the fire department in addition to law enforcement eliminated any ambiguity regarding the perspectives of Black Community members on the unity between the fire department and law enforcement, and further represented a response to the violence at the hands of firefighters in the years prior. In reality, the interactions between the fire departments and Black Community members cannot be isolated from the surrounding and historical context, but for the point of developing an understanding and awareness of the national cyclically propagating gap in

\footnotetext{
${ }^{39}$ See (Blight, 1994) for an explication of Black historical memory and identity in America and (Pendaz, 2010) for literature surrounding the collective identity of African Americans.

${ }^{40}$ The term 'turnouts' or 'bunker gear' references protective clothing worn by firefighters, including coats, pants, boots, and hood.

${ }^{41}$ Employment of the term "history" must be done carefully, with specific attention and consideration given to the difference between a hegemonic historical narrative and viscerally experienced or ancestrally inherited remembrances of the past. The passage of time has a unique characteristic that allows perpetrators to forget and grants a lens of history through which events can be recalled, while those directly impacted or harmed through the actions of the perpetrator are not afforded the same privilege (Klein, 2000). Victims and targets of harmful actions are sentenced with remembering. History affords distance from action. Remembrance, visceral and experiential recollection and manifestations. Remembrance can be generationally inherited. History is taught and can be recalled with an air of distance. This is to say that history functions as impersonal reflections and regurgitations of often hegemonically determined narratives, narratives of victors (Klein, 2000; Blight, 1994). A collective memory that aims to invoke a targeted meaning and invites the audience to adopt a memory of a survivor or witness as their own. The associated consequences of validating and employing this definition include masking structural violence, enabling continued oppression, and propagating the hegemonic narrative throughout a system. Funkenstein offers an additional influential element that "collective memory has important uses, reminding us all remembering occurs within social contexts of environment and discourse" however diverges with the conclusion that "collective awareness presumes collective memory" (Klein, p.133, 2000).
} 
relations, the Birmingham Children's Crusade, Watts Rebellion, and Rodney King Rebellion are crucial points of analysis. The generation of increased tensions on behalf of the fire department can be observed through the events of the Watts Rebellion and Rodney King Rebellion, exhibiting functional mechanisms similar to those in the generation of national symbolism of firefighters, with a massive asterisk to denote a significant facet and fundamentally problematic factor that needs to be considered. On the national scale, the Watts Rebellion and Rodney King Rebellion were broadcast in the media with near exclusive negative coverage and framing through phrasing associated with irrational destruction-invalidating the undeniable righteousness of equality for Black people in the United States (Cammarata, 2018). The tension emphasized through the national media created intense connotations and symbolism of firefighters as targets of attacks from Black Communities. This blanketed the already adrenaline-charged firefighter duty to serve and respond with layers of intricacies and increased tension. In addition, reinforcing observed structural connections between the fire department and law enforcement. Lacking the dedicated effort to previously establish rapport between the local fire department (LAFD, in the case of Watts) and Black Community leaders of Watts, the cyclically reinforcing tensions and mistrust between fire service personnel and Black Community members exacerbated and magnified.

The dynamics observed today need to be understood not only as extensions of the racial tensions of the 1960s and but further, as a result of the treatment of Black folks throughout American history. The responsibility of recognizing the broader significance and national implications of fire department actions in 1963 was overlooked by local fire departments across the country, who had and still have the opportunity to engage with Community leaders. Emphasis on the establishment of unique relationships that overtly and structurally reflect respect for Black Community needs and demonstrate intentionality in proactive communication with Black Community leaders cannot be understated. It is only through listening to Community needs, initiating Community engagement, building unequivocally conditionless programs focused on the improvement of Community health and wellbeing that the cyclically reinforcing gap in relations can be interrupted and the work towards universal fire service equity connotations can begin. 


\section{Conclusion}

The fundamental core that led to the establishment of the fire department presents a particularly significant opportunity for the fire service and local fire departments across the country to take initiative in the Communities they are tasked to serve with the intention to build rapport with Community leaders and improve dynamics in Community relations. On the local level, addressing the relational gap can improve fire service efficiency, workplace environment, Community member interactions, and the generationally inherited beliefs regarding the fire department. On a larger scale, these initiatives by fire departments across the country can take substantial institutional steps in the attempt to combat structural racism and towards rectifying historically reinforced qualitative perceptions of systemic exclusion extending to the provision of the fire service and EMS. Without recognition of the events throughout history and the significance that nationally magnified symbolism depicting the fire service had and has in the shaping of Community interactions with low-SES Black Communities, the fire service at large cannot function as a truly equitable organization.

Development of Community relations, while influenced by federal and state level governmental developments, are determined by local level interactions. With that being said, the historical significance and the national depiction of the fire service as a weaponized mechanism in the state-sanctioned oppression of Black people during the events of the 1960s cannot be understated, nor can its symbolism be separated from the development of Community relations across the country. The fire service at large was stained by the actions in Birmingham and resulted in nationally experienced ramifications in the interactions between Black Community members and fire department personnel. These moments of amplification are not all encompassing as the root or source of the relational gap, however; as systemic racism is built into the foundation of the United States and impacts all institutions, particularly those proctored and established by governmental bodies. Acknowledgement that the acts of history are not isolated to historical recollection, but rather have national significance is essential to the process of re-establishing trust between Black Community members and fire department personnel. Regardless of the initials depicted on firefighter turnout coats and helmets, this fraught history needs to be addressed on 
the local level and by fire departments throughout the United States. The core and fundamental values of firefighters across the country is not one of attaining power or control over a municipality, but rather to engage with and serve Community. I maintain that the dynamic between firefighters and emergency medical service personnel and low-SES Black Community members is not maliciously propagated, but rather stems from misaligned narratives and asynchronous awareness of national symbolism of institutions correlated with the state — including the fire service — and governmentally sanctioned, systemic infrastructural racism throughout history in legislation and institutional structure. It is exceedingly valid that low-SES Black Communities do not feel included in the population served by governmental organizations when considering the abhorrent treatment of people of color and low-SES Communities throughout American history. It is also valid to claim that firefighters believe in Community service and provisional equity, especially in the context of the origin and core values of the fire service. The task that lies ahead is the alignment of the narratives and establishment of an all-encompassing feeling of inclusion in fire and emergency medical service provision.

The values and fundamental core of the fire department cannot override or negate the systemic exclusion and oppression of Black people, however; the organizational structure presents an opportunity for individual fire department initiatives, establishment of personalized local level rapport, and institutional adaptations tailored to the needs of the Communities being served. The neglect of scholarly discourse in this field and broadly scaled consciousness regarding the significance of this relational dynamic is indicative of vast unconsciousness regarding the social and societal deviations from the hegemonic narrative. There is a need for extensive research in this field building a cooperative, interdisciplinary library on the foundation provided by the Fire Research and Safety Act publications and the small group of scholars producing work that suggests models for Community engagement, improvements to emergency management response to large-scale disasters, and fire prevention safety education. The literature produced must be interdisciplinary and cooperative if there is going to be realignment of the narratives and critical connections forged between the quantitative data that suggests equity and the qualitative work that demonstrates the relational dynamic between Black Communities and 
fire department personnel is built on a fraught history. This contradiction propagates the relational gap between low-SES Black Communities and fire service and EMS responders, and is in great need for additional inquiries and research into the observed dynamics. For progress to be made and institutional changes to be implemented, local level initiatives must be taken, literature must be cooperative — not only between fields of academia, but with incorporation of Community perspectives and reflections - and there must be recognition that while individual firefighters and fire departments did not actively participate in the state-ordered oppression of Black people, the significance of fire service symbolism extends to low-SES Black Communities throughout the United States.

Involvement in the fire service provided unquantifiable clarity for the direction I am pursuing in life and enlightened me to a Community of people who have taught me innumerable lessons about what it genuinely means to be a good person. I grew up indoctrinated in the hegemonic narrative, but truthfully, my involvement in the fire service only furthered my belief in the fundamental core of the fire department that sparked the creation of the hegemonic narrative in the first place. I observed Community dynamics that I felt intrigued by and passionate about investigating, but through my work with several fire departments, in multiple states, and interactions with hundreds of firefighters, the moral undertone and synchronicity of fire service personnel perspectives is unanimously centered around serving Community. The core of the fire department is being the first to respond to personal catastrophes of people that firefighters have probably never met and may never meet again with the sole intention of providing aid and stopping the source of catastrophic destruction. I cannot and do not attempt to speak on behalf of all firefighters, but I do believe that the definition of 'service' specifically in regards to the fire department, is not something that can be captured solely through quantitative data, but rather is displayed in small actions of preserving a family photo album or snagging the car keys off of a counter in a residential structure fire, and in the creation of Community rapport that bonds the fire service to the Community it is tasked to serve.

With the consideration that the fire service and specifically Community relations within the fire service is a drastically under-developed discourse, resulting in an overarching lack in applicable literature, 
research, and commentary into the structure, dynamics, and causality of this relational gap, a great deal of analysis and conclusions were informed through experiential observations and the incorporation of perspectives from individuals within low-SES Black Communities and fire departments across the country. This work does not seek to assign blame or to prosecute, but rather draw attention to an observed societal phenomenon and an incredibly important field of study that is often overlooked. The current cyclical gap propagation is driven by the misalignment of the narratives, beliefs, teachings, and understanding between fire service provision and Black Community historical experience. To renovate the relational dynamic between the fire department and low-SES Black Communities and progress towards provisional equity, the quintessential first step is listening to the understandings, beliefs, and needs of Community members, in addition to the perspectives of fire personnel to establish a foundation of local level personal rapport and respect. Exemplified through moments of amplification, actions throughout U.S. history were not contained to one fire department, but rather stained the fire service at large. Further, the moments of amplification provided tangible illustrations demonstrating that governmentally sanctioned systemic racism and oppression led to the mistrust and skepticism of all state-orchestrated institutions, including the fire service. The hegemonic national narrative connects, but differentiates between police and fire services, however; the perspective within Black Communities does not universally reflect the differentiation. The acknowledgement of history and the symbolism throughout low-SES Black Communities that drove the deviation from the hegemonic narrative - portraying the fire service as heroes - is necessary to foster an environment to begin establishing trust.

Local level Community outreach and engagement drives local level relational change. Change on the local level is particularly significant in regards to provisional dynamics involving the fire department because the fire department, while represented by the IAFC on the federal-level, is a locally organized and overseen, Community-based service. The foundational principles of which are maintained as integral components to the core of the fire service today. The origination as a all-encompassing Community organization provides the fire service with a unique opportunity to realign narratives and reestablish relations with the Communities they are tasked to serve. Principally, the contradiction in discourse must 
be collaboratively realigned to progress towards the provisional equity in fire and emergency medical services. 


\section{References ${ }^{42}$}

Ahlbrandt, R. S. (1972). Efficient Output of a Quasi-public Good--Fire Services. University of Washington.

Adio, O. A., Ikuma, L., \& Wiley, S. (2020). Management of frequent ED users by community paramedics improves patient experiences and reduces EMS utilization. Patient Experience Journal, 7(3), 174-188.

Advisory Commission on Intergovernmental Relations, \& Reeves, M. M., The Federal role in local fire protection (1980). Washington, D.C.; Superintendent of Documents, U.S. G.P.O.

Alter, D. A., Stukel, T., Chong, A., \& Henry, D. (2011). Lesson from Canada's universal care: socially disadvantaged patients use more health services, still have poorer health. Health Affairs, 30(2), 274-283.

"America Burning: Report of the National Commission on Fire Prevention and Control NCFPC, Washington. DC. U.S Government Printing Office, May 1973.

Bailey, R. (1973). Economic aspects of the black internal colony. The Review of Black Political Economy, 3(4), 43-72.

Beaumont, J. R. (1981). Location-allocation problems in a plane a review of some models. Socio-economic planning sciences, 15(5), 217-229.

Bentley, G. R. (2017). A History of the Freedmen's Bureau. University of Pennsylvania Press.

Bindas, K. J. (2010). Re-remembering a segregated past: Race in American memory. History \& Memory, 22(1), 113-134

Blackwell, J. (1975). The Black community: Diversity and unity. New York: Harper \& Row.

Blight, D. W. (1994). WEB Du Bois and the struggle for American historical memory. History and memory in African-American culture, 45-71.

Bloom, J. \& Martin Jr, W. E. (2013). Black against Empire: The History and Politics of the Black Panther Party.

Brown, G. C., Vigil, J. D., \& Taylor, E. R. (2012). The ghettoization of Blacks in Los Angeles: The emergence of street gangs. Journal of African American Studies, 16(2), 209-225.

Burton, Brent. (2021) The History of Black Firefighters in Los Angeles. African American Firefighter Museum Historical Timeline, African American Firefighter Museum. www.aaffmuseum.org/wp-content/uploads/2012/11/Black-firefighter-timeline.pdf.

Cammarata, S. L. (2016). The Watts riots: a contemporary study of the news coverage of the riots (Doctoral dissertation, University of Missouri--Columbia).

Castle Rock v. Gonzales. (2005). Oyez. Retrieved from https://www.oyez.org/cases/2004/04-278

"Chapter 2: History and Current State of EMS." Institute of Medicine. (2007) Emergency Medical Services: At the Crossroads. Washington, DC: The National Academies Sciences Engineering Medicine Press. doi: 10.17226/11629.

\footnotetext{
${ }^{42}$ Sources used in the construction of this map of history do not solely look to published scholarly works, and include sources that discuss a less academically acknowledged side of history. The sources are cited in scholarly and publicly available works, for example FIREFIGHTERS, a book written and published by the National Fallen Firefighters Foundation, and History of Black Firefighters by Michael Legeros et al.
} 
Clarke, A. Y., \& McCall, L. (2013). Intersectionality and social explanation in social science research. $D u$ Bois Review: Social Science Research on Race, 10(2), 349-363.

Clarke, J., \& Kaleem, N. (2010). Equality, vulnerability, risk, and service delivery: equality improvement in fire and rescue services. International Fire Service Journal of Leadership and Management, 4(2), 13-22.

Compton F.D. (n.d.). Compton Fire Department. City of Compton - Fire Department. http://www.comptoncity.org/depts/fire/default.asp.

Corcoran, J., Higgs, G., Brunsdon, C., Ware, A., \& Norman, P. (2007). The use of spatial analytical techniques to explore patterns of fire incidence: A South Wales case study. Computers, Environment and Urban Systems, 31(6), 623-647.

Cruess, R. L., \& Cruess, S. R. (2008). Expectations and obligations: professionalism and medicine's social contract with society. Perspectives in biology and medicine, 51(4), 579-598.

Crumpler, R. L. (1883). A book of medical discourses: in two parts. Cashman, Keating \& Company, Printers.

Dana, D. D. (1858). The Fireman: The Fire Departments of the United States, with a Full Account of All Large Fires, Statistics of Losses and Expenses, Theatres Destroyed by Fire... J. French.

Davies, S., \& Huff, D. L. (1972). Impact of ghettoization on black employment. Economic Geography, 48(4), 421-427.

Ditzel, Paul. (1986) The LAFD Centennial "History of the Black Firemen." Los Angeles City Fire Department, 1886-1986, Los Angeles Firemen's Relief Association, pp. 92, 146-153.

Downs, J. (2012). Sick from freedom: African-American illness and suffering during the Civil War and Reconstruction. Oxford University Press.

Evans Jr, C. A. (1993). Public health impact of the 1992 Los Angeles civil unrest. Public Health Reports, 108(3), 265.

Evans, K. R., \& Gusmano, M. K. (2021). Civic Learning, Science, and Structural Racism. Hastings Center Report, 51, S46-S50.

Forster, T. (2014). Why do Fire Departments provide Emergency Medical Services? Plumas County Fire Chiefs Association.

https:/www.plumasfirechiefs.org/why-do-fire-departments-provide-emergency-medical-services.

Getz, M. (1979). The economics of the urban fire department. Johns Hopkins University Press.

Gomersall, C. (2003). Access to public services: An analysis of fire department response times in cincinnati. (Order No. 3109709, University of Cincinnati). ProQuest Dissertations and Theses, 123.

Hadden, S. E. (2003). Slave patrols: Law and violence in Virginia and the Carolinas. Harvard University Press.

Hansen, C. (2019, July 10). Slave Patrols: An Early Form of American Policing. National Law Enforcement Museum. https://lawenforcementmuseum.org/2019/07/10/slave-patrols-an-early-form-of-american-policing

Hansen Löfstrand, C. (2019). Marketization in a state-centred policing context: The case of Sweden. European Journal of Criminology, 1477370819882905.

Hastie, C. (2014). Trust, inequality and the Fire Service. Social Relations, Transformation and Trust Conference, Coventry, United Kingdom.

Hughes, J. R., \& Cain, L. P. (2011). American economic history. Prentice Hall. 
IAFC Board of Directors . (2009, May 7). Position on Fire-Based Emergency Medical Services . IAFC Position Statement.

https://www.iafc.org/about-iafc/positions/position/iafc-position-fire-based-emergency-medical-ser vices.

Jacobs, E. A., Rolle, I., Ferrans, C. E., Whitaker, E. E., \& Warnecke, R. B. (2006). Understanding African Americans' views of the trustworthiness of physicians. Journal of general internal medicine, 21(6), 642-647.

Jennings, C. R. (1999). Socioeconomic characteristics and their relationship to fire incidence: a review of the literature. Fire technology, 35(1), 7-34

Jennings, C. R. (1997). An Empirical Analysis of Building Stock and Socio-economic Characteristics for Memphis Tennessee. Unpublished.

Jennings, C. R. (2013). Social and economic characteristics as determinants of residential fire risk in urban neighborhoods: A review of the literature. Fire Safety Journal, 62, 13-19.

Johnson, D. (2007). Martin Luther King Jr.'s 1963 Birmingham Campaign as Image Event. Rhetoric \& Public Affairs, 10(1), 1-25. doi:http://dx.doi.org.proxy.lib.pdx.edu/10.1353/rap.2007.0023

Johnson Jr, J. H., Jones, C. K., Farrell Jr, W. C., \& Oliver, M. L. (1992). The Los Angeles rebellion: A retrospective view. Economic Development Quarterly, 6(4), 356-372.

Jones, D. K. (2019). Political participation in the least healthy place in America: examining the political determinants of health in the Mississippi Delta. Journal of Health Politics, Policy and Law, 44(3), 505-531.

Kappeler, V. E. (2014). A brief history of slavery and the origins of American policing. Police Studies Online.

Kelly, J. E. L., Yatsuk, R. A., \& Routley, J. G. (2003). Firefighters. National Fallen Firefighters Foundation.

Kennedy, B. R., Mathis, C. C., \& Woods, A. K. (2007). African Americans and their distrust of the health care system: healthcare for diverse populations. Journal of cultural diversity, 14(2).

Kerner, O. the National Advisory Commission on Civil Disorders (1968). Report of the National Advisory.

Kiran, K. C., Corcoran, J., \& Chhetri, P. (2020). Measuring the spatial accessibility to fire stations using enhanced floating catchment method. Socio-Economic Planning Sciences, 69, 100673.

Klein, K. L. (2000). On the emergence of memory in historical discourse. Representations, 69, 127-150

Knowlton, A., Weir, B. W., Hughes, B. S., Southerland, R. H., Schultz, C. W., Sarpatwari, R., ... \& Gaasch, W. (2013). Patient demographic and health factors associated with frequent use of emergency medical services in a midsized city. Academic Emergency Medicine, 20(11), 1101-1111.

Kuswa, K. D. (2002). Suburbification, Segregation, and the Consolidation of the Highway Machine. JL Soc'y, 3, 31 .

L.A. County. (2018, June 12). Geography \& Statistics. County of Los Angeles. https://lacounty.gov/government/geography-statistics/.

LAFD. (n.d.). FireStatLA. Los Angeles Fire Department. https://www.lafd.org/fsla/stations-map?year=2020.

Lambert, T. (2017). Public (and Quasi-Public) Goods. In How to Regulate: A Guide for Policymakers (pp. 60-90). Cambridge: Cambridge University Press. doi:10.1017/9781316534885.006.

Lee, M. J., Reddy, K., Chowdhury, J., Kumar, N., Clark, P. A., Ndao, P., ... \& Song, S. (2018). 
Overcoming the legacy of mistrust: African Americans' mistrust of medical profession.

Legeros, M. J., Milligan, C., \& Rev. Ballew, R. (n.d.). History of Black Firefighters. https://www.legeros.com/history/ebf/national.shtml\#.

LOC. (1861). Fire next door to Willard's Hotel, Washington, D.C. Ellsworth's New York fire Zouaves extinguishing the flames / / from a sketch by our special artist. The Library of Congress. https://www.loc.gov/item/2014649269/.

Logan, J. R., Zhang, W., Turner, R., \& Shertzer, A. (2015). Creating the black ghetto: Black residential patterns before and during the Great Migration. The Annals of the American Academy of Political and Social Science, 660(1), 18-35.

Lozito v. New York City (NY State Supreme Court 2013).

Lyons, P. R. (1976). Fire in America!. National Fire Protection Assn.

Marable, M. (2011). How capitalism underdeveloped Black America: Problems in race, political economy, and society. Cambridge, MA: South End Press.

McAllister, D. M. (1976). Equity and efficiency in public facility location. Geographical analysis, 8(1), 47-63.

McCone, J. A., \& Christopher, W. M. (1965). Violence in the city: an end or a beginning? A report by the Governor's Commission on the Los Angeles Riots. Los Angeles: Commission on the Los Angeles Riots.

National Law Enforcement Museum: https://lawenforcementmuseum.org/2019/07/10/slave-patrols-an-early-form-of-american-policing

National Museum of African American History and Culture. (2020, July 20). Historical Foundations of Race. National Museum of African American History and Culture. https://nmaahc.si.edu/learn/talking-about-race/topics/historical-foundations-race.

Nelson, A. (2011). Body and soul: The Black Panther Party and the fight against medical discrimination. University of Minnesota Press.

New York State Military Museum and Veterans Research Center. (n.d.). 11th New York Infantry Regiment's Civil War Newspaper Clippings. New York State Military Museum and Veterans Research Center ::11th Infantry Regiment . https://museum.dmna.ny.gov/unit-history/infantry/11th-infantry-regiment/newspaper-clippings.

NFPA, Municipal Fire Service Workbook, prepared by Research Triangle Institute, International City Management Association, and the National Fire Protection Association for the National Science Foundation, (1977) Washington, DC, U.S. Government Printing Office.

Pendaz, S. (2010). Collective identity and African American views of Africa, African immigrants, and immigrant entitlements.

Potter, G. (2013). The history of policing in the United States. EKU School of Justice Studies. https://plsonline.eku.edu/sites/plsonline.eku.edu/files/the-history-of-policing-in-us.pdf

Pozner, C. N., Zane, R., Nelson, S. J., \& Levine, M. (2004). International EMS systems: the United States: past, present, and future. Resuscitation, 60(3), 239-244.

Quarantelli, E. L. (2000). Disaster planning, emergency management and civil protection: The historical development of organized efforts to plan for and to respond to disasters.

Reeves, M.M. (1980). See above: Advisory Commission on Intergovernmental Relations \& Reeves, M.M., 1980.

Rucker, D. W., Edwards, R. A., Burstin, H. R., O'Neil, A. C., \& Brennan, T. A. (1997). Patient-specific predictors of ambulance use. Annals of emergency medicine, 29(4), 484-491. 
Schafer, W., Carroll, J., Haynes, S. \& Abrams, S. (2008). Emergency Management Planning as Collaborative Community Work. Journal of Homeland Security and Emergency Management, 5(1). https://doi.org/10.2202/1547-7355.1396

Shah M. N. (2006). The formation of the emergency medical services system. American journal of public health, 96(3), 414-423. https://doi.org/10.2105/AJPH.2004.048793

Skloot, R. (2017). The immortal life of Henrietta Lacks. Broadway Paperbacks.

Smith, D. B. (2005). Racial and ethnic health disparities and the unfinished civil rights agenda. Health Affairs, 24(2), 317-324.

Smith, R., Wright, M., \& Solanki, A. (2008). Analysis of fire and rescue service performance and outcomes with reference to population socio-demographics. Department for Communities and Local Government Publications.

Sokoloff, K. L., \& Engerman, S. L. (2000). Institutions, factor endowments, and paths of development in the new world. Journal of Economic perspectives, 14(3), 217-232.

Solomon, W. L., \& Solomon, W. S. (2004). Images of Rebellion: News Coverage of Rodney King. Race, Gender \& Class, 23-38.

Spitzer, S., \& Scull, A. T. (1977). Privatization and capitalist development: the case of the private police. Social problems, 25(1), 18-29.

Staff, F. E. (2001, December 1). Firefighter Involvement in Law Enforcement Activities. Fire Engineering. https:/www.fireengineering.com/firefighting/firefighter-involvement-in-law-enforcement-activiti es/\#gref.

"State Government Fire Programs," Fireword, (1977) Washington, DC, National Fire Prevention and Control Administration, U.S. Department of Commerce.

Taney, R. B. \& Supreme Court Of The United States. (1856) U.S. Reports: Dred Scott v. Sandford, 60 U.S. 19 How. 393. [Periodical] Retrieved from the Library of Congress, https://www.loc.gov/item/usrep060393a/.

Thomas, S. B., \& Casper, E. (2019). The burdens of race and history on black people's health 400 years after Jamestown.

Till R.C., Coon J.W. (2019) Fire Protection. Springer, Cham. https://doi.org/10.1007/978-3-319-90844-1_4

Toregas, C., Swain, R., ReVelle, C., \& Bergman, L. (1971). The Location of Emergency Service Facilities. Operations Research, 19(6), 1363-1373.

Turner, K. B. , Giacopassi , D. , \& Vandiver , M. (2006) . Ignoring the Past: Coverage of Slavery and Slave Patrols in Criminal Justice Texts. Journal of Criminal Justice Education, 17: (1), 181-195.

U.S. Department of Transportation, NHTSA; U.S. Department of Commerce, NTI, 911 Task Force; Reinke, R. W., Status of legislation concerning 911: the emergency telephone number, with a suggested 911 Emergency Telephone Number Act with supporting analysis (1979). Washington, D.C.; Government Printing Office, Washington, D.C.

Walker, D. C. (2011). Mass notification and crisis communications: Planning, preparedness, and systems. CRC Press.

Warheit, G., and Quarantelli, E. L. Office of Civil Defense (1969) pp. 1-90, An Analysis of Los Angeles Fire Department Operations During Watts.

Warren v. District of Columbia (1981) (https://www.cadc.uscourts.gov/internet/opinions.nsf/514377BDB0E6AE7885257A3E004EC100 /\$file/11-7001-1383997.pdf). 
Washington, H. A. (2006). Medical apartheid: The dark history of medical experimentation on Black Americans from colonial times to the present. Doubleday Books.

Waud, A. R. (1861) Gallant conduct of Ellsworth's Zouaves, in their successful endeavor to save Willard's Hotel, Washington / sketch by A. Waud. Washington D.C, 1861. [Photograph] Retrieved from the Library of Congress, https://www.loc.gov/item/2006677587/.

Webster, William H. (1992). "The City in Crisis: A Report by the Special Advisor to the Board of Police Commissioners on the Civil Disorder in Los Angeles." Los Angeles, CA: Special Advisor Study

WHHA. (1861). Illustration of a fire at Willard's Hotel. The White House Historical Association. https://www.whitehousehistory.org/photos/illustration-of-a-fire-at-willards-hotel.

Williams, D. R., \& Jackson, P. B. (2005). Social sources of racial disparities in health. Health affairs, 24(2), 325-334.

Wingspread Conference on Fire Service Administration, Education, and Research (1966) Statements of National Significance to the Fire Problem in the United States. Racine, WI, The Johnson Foundation.

Woodson, C. G. (2006). The mis-education of the Negro. Book Tree.

Yao, J., Zhang, X., \& Murray, A. T. (2019). Location optimization of urban fire stations: Access and service coverage. Computers, Environment and Urban Systems, 73, 184-190. 


\section{Appendices}

\section{A. Maps of Los Angeles}
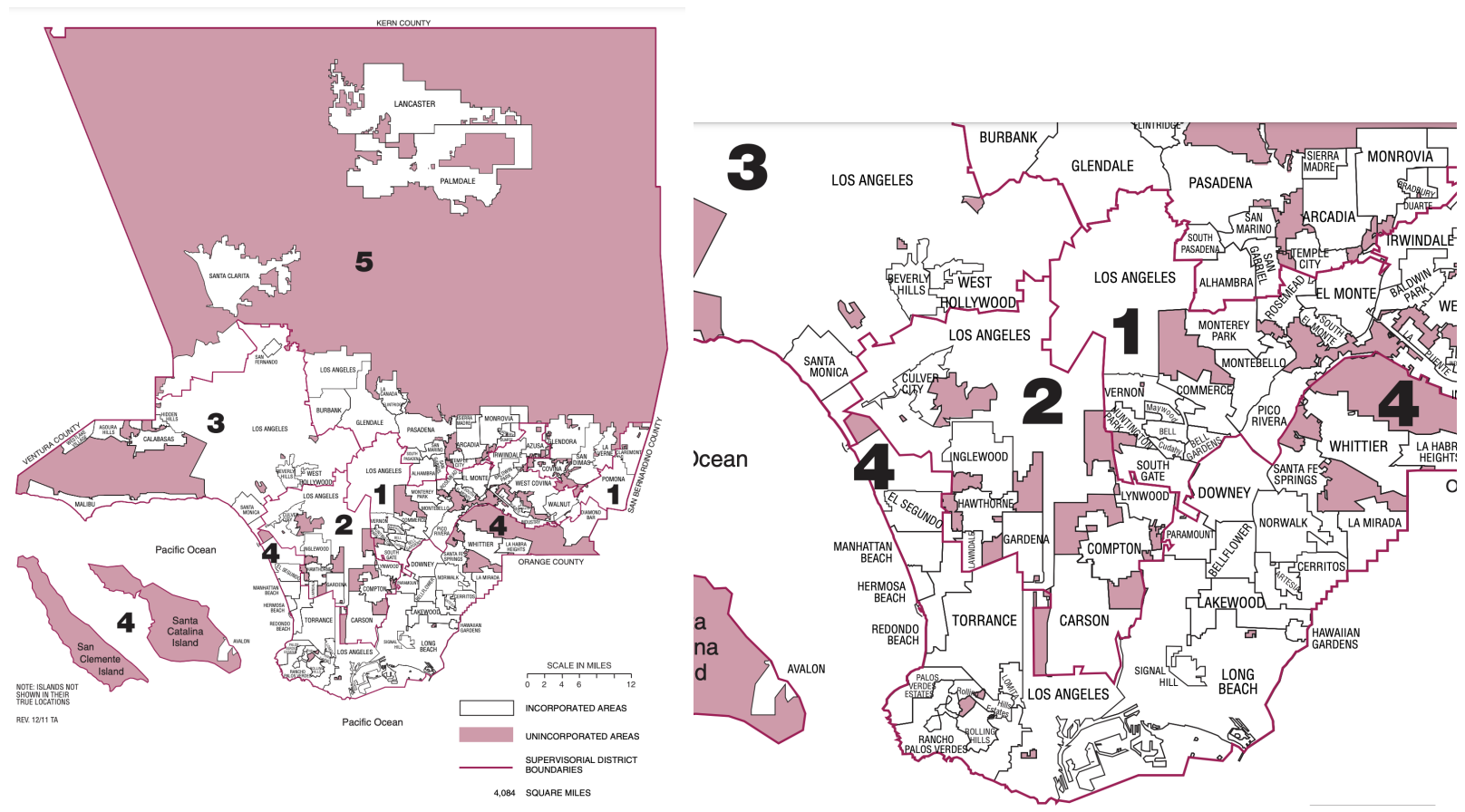

Fig. 1. Maps depicting the cities municipality boundaries in Los Angeles County. On the left the whole county is captured, while the right is a magnified image to clarify the area this work is focused on.

Los Angeles County Map (all Cities \& Districts) from Dept. of LA County.; "LACo Cities Map"; LA County; lacounty.gov http://file.lacounty.gov/SDSInter/lac/1043452 BasicColorMap.pdf. 


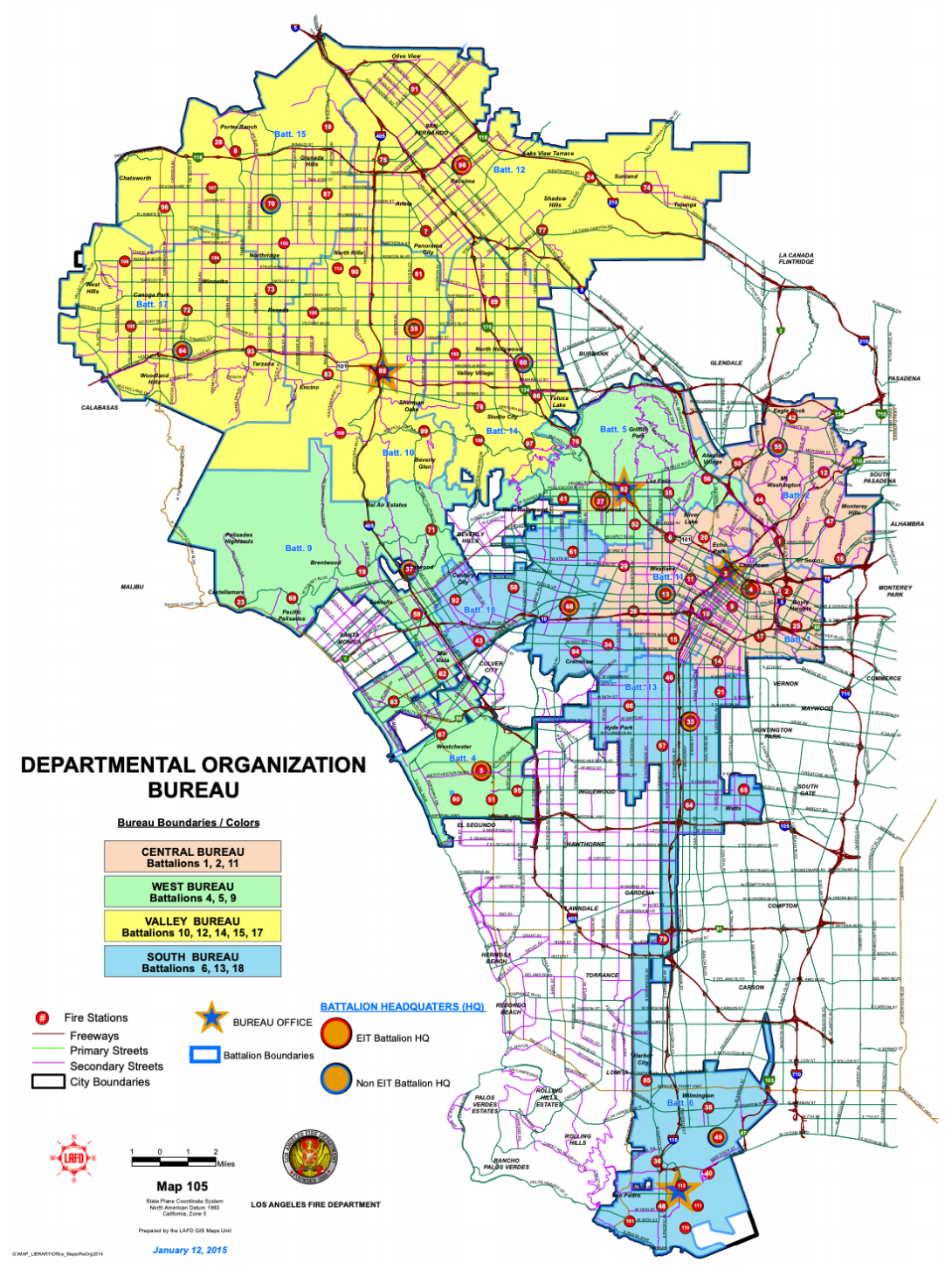

Fig. 2: Los Angeles Fire Department Battalion Lines;

LAFD Battalion Boundaries Map from LAFD.; "LAFD Bureaus Map"; LAFD; lafd.org https://www.lafd.org/lafd-bureaus-map 


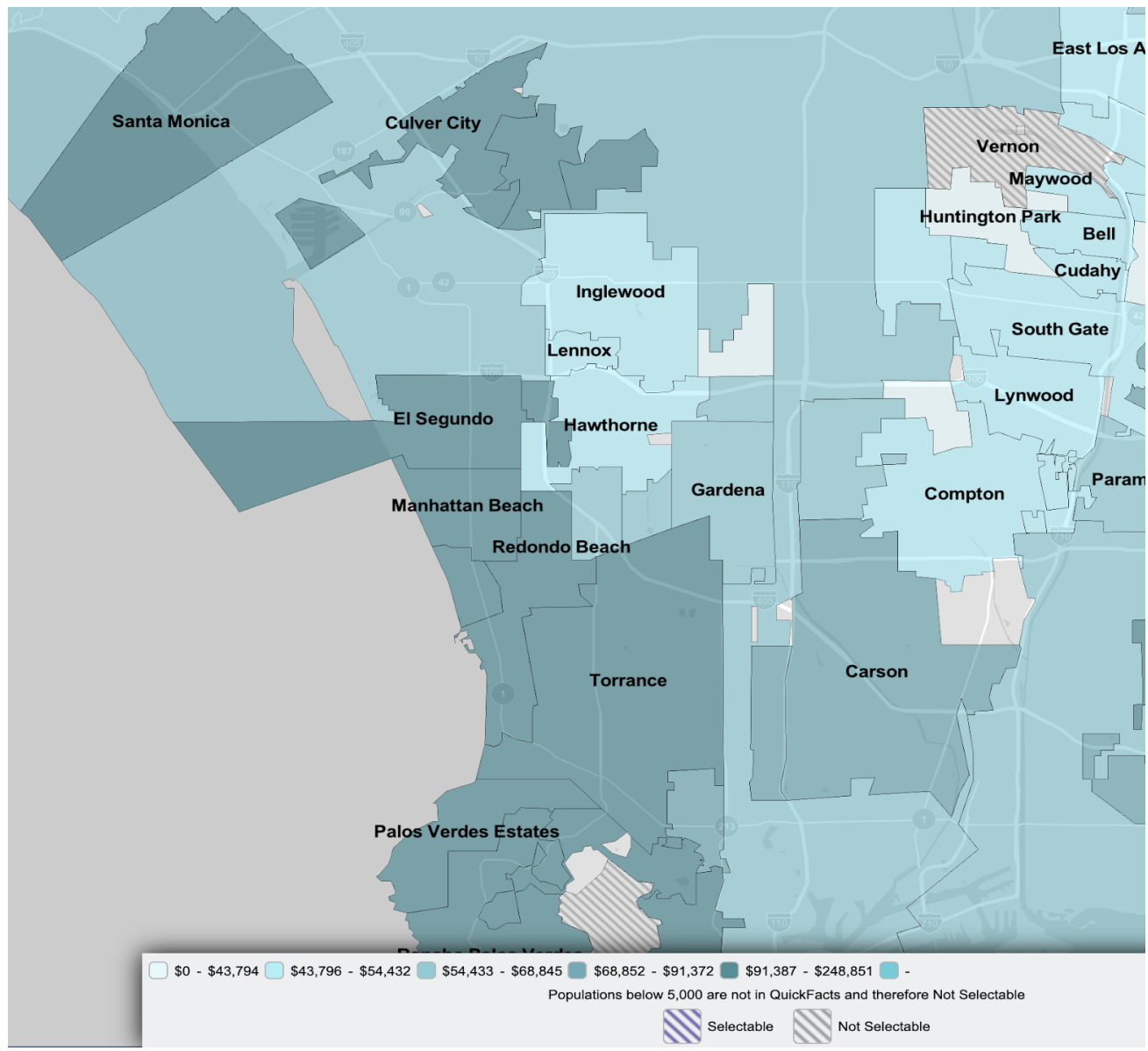

Fig. 3: Census Income Distribution of Los Angeles; Census Data; "Median Household Income (in 2019 dollars)"; Census Los Angeles County; census.gov https://www.census.gov/quickfacts/fact/map/losangelescountycalifornia,US/INC110219 


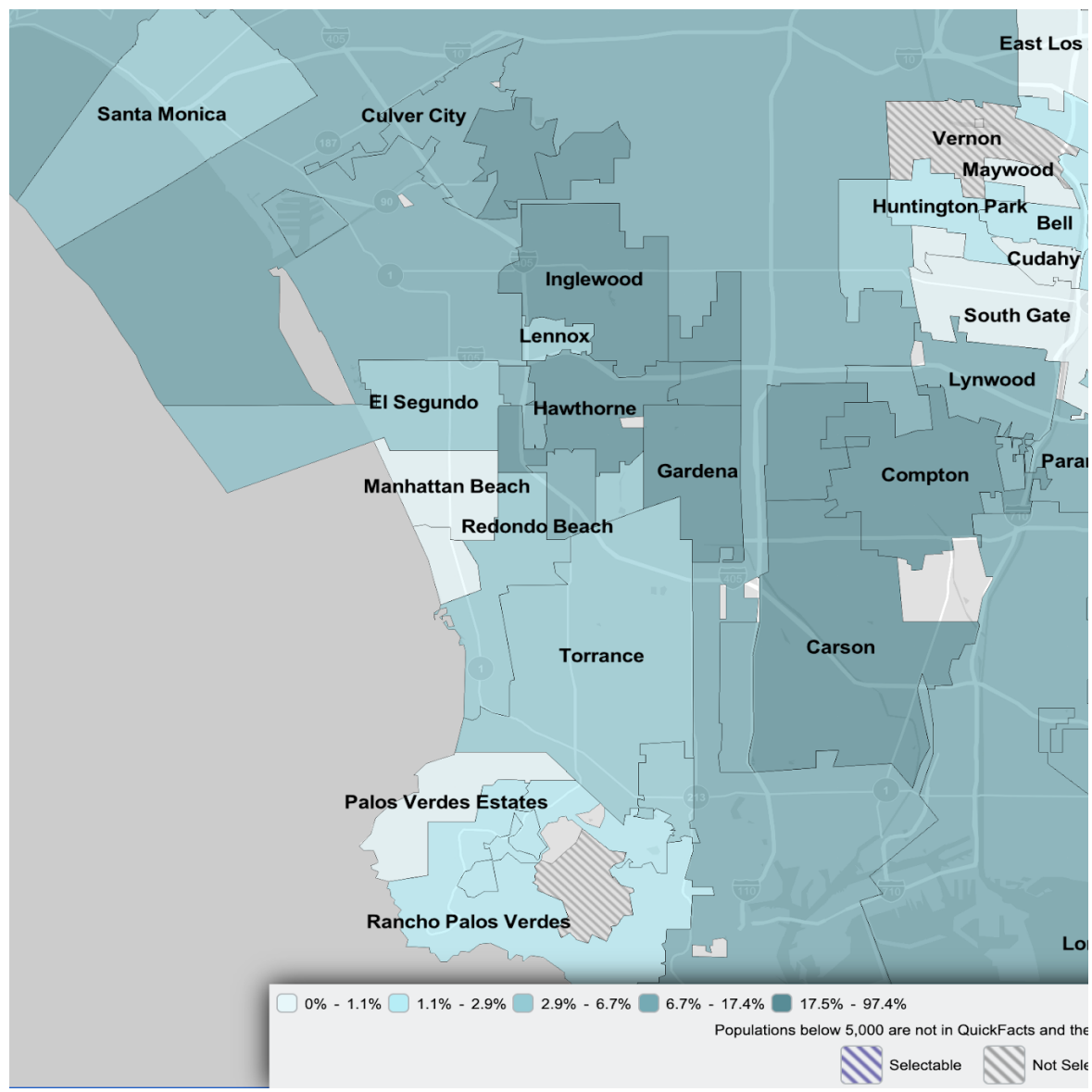

Fig. 4: Distribution of the African American Population in Los Angeles;

Census Data; "Black or African American alone, percent"; Census Los Angeles County; census.gov https:/www.census.gov/quickfacts/fact/map/losangelescountycalifornia,US/RHI225219 


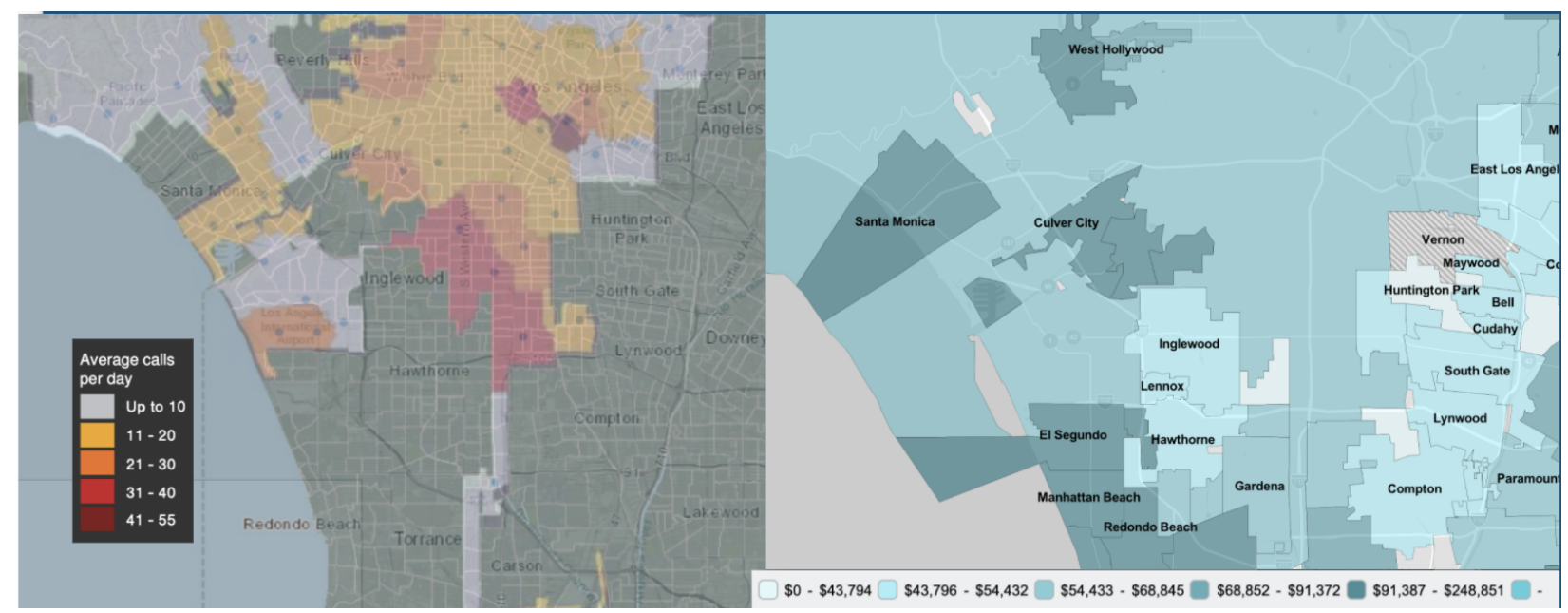

Fig. 5: Comparison of Call Volume Data (left) and Median Household Income (right);

LAFD Strategic Plan (right) "Average Calls Per Day by District”; Los Angeles Fire Department; lafd.org https://issuu.com/lafd/docs/strategic plan final_2018.02.09? e=17034503/59029441

Census Data; "Median Household Income (in 2019 dollars)"; Census Los Angeles County; census.gov https://www.census.gov/quickfacts/fact/map/losangelescountycalifornia,US/INC110219

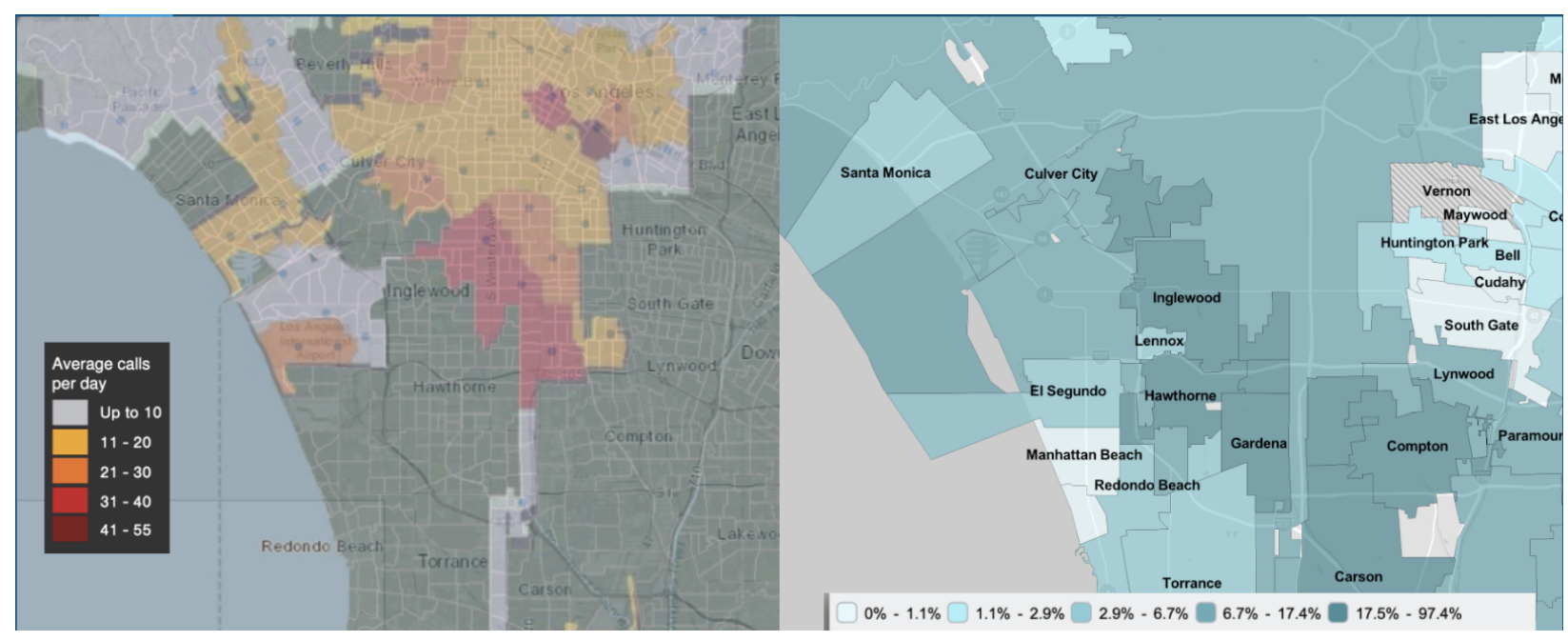

Fig. 6: Comparison of Call Volume Data (left) and Distribution of African American Population (right); LAFD Strategic Plan (right) "Average Calls Per Day by District"; Los Angeles Fire Department; lafd.org https://issuu.com/lafd/docs/strategic plan final 2018.02.09? e =17034503/59029441

Census Data; "Black or African American alone, percent"; Census Los Angeles County; census.gov https://www.census.gov/quickfacts/fact/map/losangelescountycalifornia,US/RHI225219 


\section{B. Abbreviations Key}

EMS -- Emergency Medical Services

EMT -- Emergency Medical Technician

FMA -- Fire Management Area

FRSA -- Fire Research Safety Act

GIS -- Geographic Information System

IABPFF -- International Association of Black Professional Fire Fighters

IAFC -- International Association of Fire Chiefs

IAFF -- International Association of Fire Fighters

LAFD -- Los Angeles Fire Department

LACoFD -- Los Angeles County Fire Department

LEAA -- Law Enforcement Assistance Administration

NFFF -- National Fallen Firefighters Foundation

NFPA -- National Fire Protection Association

NFPCA -- National Fire Prevention and Control

NHTSA -- National Highway Traffic Safety Administration

SCLC -- Southern Christian Leadership Conference

SES -- Socioeconomic Status

SOP -- Standard Operating Procedure 